\title{
IL-10 lentivirus-laden hydrogel tubes increase spinal progenitor survival and neuronal differentiation after spinal cord injury
}

\author{
Andrew Ciciriello ${ }^{1}$, Dominique Smith ${ }^{2}$, Mary Munsell ${ }^{2}$, Sydney Boyd ${ }^{1}$, Lonnie Shea ${ }^{2}$, and \\ Courtney Dumont ${ }^{1}$ \\ ${ }^{1}$ University of Miami \\ ${ }^{2}$ University of Michigan
}

February 13, 2021

\begin{abstract}
The pathophysiological response following spinal cord injury (SCI) is characterized by a complex cellular cascade that limits regeneration. Biomaterial and stem cell combination therapies have shown synergistic effects, compared to their interventions independent of each other, and represent a promising approach towards regaining function after injury. In this study, we combine our polyethylene glycol (PEG) cell delivery platform with lentiviral-mediated overexpression of the anti-inflammatory cytokine interleukin (IL)-10 to improve embryonic day 14 (E14) spinal progenitor transplant survival. PEG tubes loaded with lentivirus encoding for IL-10 were implanted immediately following injury into a mouse SCI hemisection model. Two weeks after tube implantation, mouse E14 spinal progenitors were injected directly into the integrated tubes, which served as a soft substrate for cell transplantation. Together, the tubes with the IL-10 encoding lentivirus improved E14 spinal progenitor survival, assessed at two weeks post-transplantation (four weeks post-injury). Mice receiving IL-10 lentivirus-laden tubes had on average $8.1 \%$ of E14 spinal progenitors survive compared to $0.7 \%$ in mice receiving transplants without tubes, an 11.5 -fold difference. Surviving E14 spinal progenitors gave rise to neurons when injected into tubes. Additionally, axon elongation and remyelination was observed, in addition to a faster rate of functional recovery in mice receiving anti-inflammatory tubes with E14 spinal progenitor delivery. This system affords increased control over the transplantation microenvironment, offering the potential to improve stem cell-mediated tissue regeneration.
\end{abstract}

Title: IL-10 lentivirus-laden hydrogel tubes increase spinal progenitor survival and neuronal differentiation after spinal cord injury

Authors and Affiliations:

Andrew J. Ciciriello ${ }^{1,2}$, Dominique R. Smith ${ }^{3}$, Mary K. Munsell ${ }^{3}$, Sydney J. Boyd ${ }^{1}$, Lonnie D. Shea ${ }^{3,4}$, and Courtney M. Dumont ${ }^{1,2, *}$

${ }^{1}$ Department of Biomedical Engineering, University of Miami, Coral Gables, FL, USA

${ }^{2}$ DJTMF Biomedical Nanotechnology Institute at the University of Miami (BioNIUM), University of Miami, Miami, FL, USA

${ }^{3}$ Department of Biomedical Engineering, University of Michigan, Ann Arbor, MI, USA

${ }^{4}$ Department of Chemical Engineering, University of Michigan, Ann Arbor, MI, USA

\section{${ }^{*}$ Corresponding Author}

Courtney M. Dumont

Department of Biomedical Engineering, University of Miami 


\title{
1251 Memorial Drive
}

Coral Gables, FL 33156

Email: cdumont@miami.edu

Phone: (305) 243-6142

\section{ORCID iD:}

Courtney M. Dumont - 0000-0001-8455-7188

Lonnie D. Shea - 0000-0002-9296-9673

Funding Information: This work was supported by the NIH (R01EB005678).

\begin{abstract}
The pathophysiological response following spinal cord injury (SCI) is characterized by a complex cellular cascade that limits regeneration. Biomaterial and stem cell combination therapies have shown synergistic effects, compared to their interventions independent of each other, and represent a promising approach towards regaining function after injury. In this study, we combine our polyethylene glycol (PEG) cell delivery platform with lentiviral-mediated overexpression of the anti-inflammatory cytokine interleukin (IL)-10 to improve embryonic day 14 (E14) spinal progenitor transplant survival. PEG tubes loaded with lentivirus encoding for IL-10 were implanted immediately following injury into a mouse SCI hemisection model. Two weeks after tube implantation, mouse E14 spinal progenitors were injected directly into the integrated tubes, which served as a soft substrate for cell transplantation. Together, the tubes with the IL-10 encoding lentivirus improved E14 spinal progenitor survival, assessed at two weeks post-transplantation (four weeks post-injury). Mice receiving IL-10 lentivirus-laden tubes had on average $8.1 \%$ of E14 spinal progenitors survive compared to $0.7 \%$ in mice receiving transplants without tubes, an 11.5-fold difference. Surviving E14 spinal progenitors gave rise to neurons when injected into tubes. Additionally, axon elongation and remyelination was observed, in addition to a faster rate of functional recovery in mice receiving anti-inflammatory tubes with E14 spinal progenitor delivery. This system affords increased control over the transplantation microenvironment, offering the potential to improve stem cell-mediated tissue regeneration.
\end{abstract}

Keywords: spinal cord injury, neural stem cells, biomaterials, gene delivery, tissue engineering

Introduction

Spinal cord injury (SCI) is an incredibly devastating condition that can leave patients both physically and financially burdened for the remainder of their lives. Approximately 12,500 new cases of traumatic SCI are reported annually in North America alone, with lifetime healthcare costs averaging about $\$ 2.35$ million per patient (Alizadeh, Dyck, \& Karimi-Abdolrezaee, 2019). Difficulties in treating SCI arise as both the innate and adaptive immune responses attempting to protect the spinal cord from further damage. The immune response, while necessary for removing dead cells and debris, creates an inhospitable milieu characterized by a cascade of cellular and biochemical signals, highlighting a delicate balance between neuroplasticity and further damage. Known as the secondary injury, this induced damage persists through acute, sub-acute, and chronic stages of injury, spanning hours to months post-SCI (Dalamagkas, Tsintou, Seifalian, \& Seifalian, 2018; Donnelly \& Popovich, 2008; Dumont, Margul, \& Shea, 2016) resulting in glial and fibrotic scarring (Bradbury \& Burnside, 2019; Hackett \& Lee, 2016; Soderblom et al., 2013; Zhu, Soderblom, Trojanowsky, Lee, \& Lee, 2014), axonal dieback and demyelination (Busch, Horn, Silver, \& Silver, 2009; Hill, 2017), apoptosis (X. Z. Liu et al., 1997), and oxidative stress (Hall, 2011) severely limiting regenerative potential.

Exogenous stem cell transplantation is a promising technique that is highly dependent on the transplantation microenvironment. Cell transplantations have shown initial promise both broadly in tissue engineering (Kwon, Kwon, Lee, Park, \& Kim, 2018) and specifically in SCI repair models (Dulin \& Lu, 2014). On a cellular level, neural stem cell (NSC) transplants repopulate lost neural and glial cells in damaged tissue (Dulin \& Lu, 2014; Mortazavi et al., 2015) in addition to working on a molecular level through cytokine and 
chemokine release post-SCI (P. Lu, Jones, Snyder, \& Tuszynski, 2003). Furthermore, transplanted NSCs can integrate with endogenous neural circuitry (Ceto, Sekiguchi, Takashima, Nimmerjahn, \& Tuszynski, 2020; Kumamaru et al., 2018) and can significantly decrease local expression of pro-inflammatory cytokines (Cheng et al., 2016). Altogether, NSCs exhibit numerous pro-regenerative functions that are highly contingent on cell survival post-transplantation. Transplantation method, medium, location, and cell age all play pivotal roles in influencing survival (Chen, Bernreuther, Dihné, \& Schachner, 2005; Karimi-Abdolrezaee, Eftekharpour, Wang, Morshead, \& Fehlings, 2006; Nagoshi et al., 2018), but perhaps the most important factor to consider with cell therapies is their transplantation microenvironment. In SCI, NSC delivery is complicated by the persisting secondary injury. As the immune response clears damaged cells and cell debris, transplanted cells are also subjected to inhospitable conditions, leading to poor survival and limited regenerative effect. SCI cell transplantation strategies commonly delay delivery to occur after an initial wave of post-injury inflammation (Tetzlaff et al., 2011). Starting hours after injury, inflammatory cytokines including interleukin (IL)-1 $\beta$, tumor necrosis factor $\alpha(\mathrm{TNF} \alpha)$, IL-6, and leukemia inhibitory factor (LIF) are strongly activated in the wound area, but their concentrations decrease by 1 week post-injury. Similarly, reactive oxygen species peak in concentration approximately 12 hours after injury, but by 1 week post-injury, their concentration drops precipitously (Donnelly \& Popovich, 2008; Dumont et al., 2016; Lacroix, Chang, Rose-John, \& Tuszynski, 2002; Shamash, Reichert, \& Rotshenker, 2002). Avoiding these inflammatory mediators by delaying transplantation has the potential to improve survival, but further intervention is required for cell transplants to have their intended regenerative effects.

Biomaterial interventions have proven to be effective following SCI in shifting the post-injury microenvironment and improving regeneration (Shuo Liu, Xie, \& Wang, 2019; Straley, Foo, \& Heilshorn, 2010) making them promising candidates to be used in combination therapies with stem cell transplants (Shengwen Liu, Schackel, Weidner, \& Puttagunta, 2018; Shrestha et al., 2014) where the goal is to create a more hospitable transplantation environment to improve transplant survival. Highly porous, polymeric scaffold implants can facilitate regeneration in the spinal cord, where the porosity allows for endogenous progenitor infiltration, aiding in axonal regrowth and myelination (Pawar et al., 2015; Shahriari, Koffler, Tuszynski, Campana, \& Sakamoto, 2017; Straley et al., 2010; Tuinstra et al., 2012; Tuinstra et al., 2013; Y. Yang et al., 2009). Furthermore, implantable scaffolds provide a defined architecture that directs axonal elongation. Softer, hydrogel based implants fabricated from polyethylene glycol (PEG) microspheres have also proved to support regeneration (Dumont et al., 2019). Macroporous tubes, molded from PEG microspheres, function similar to rigid, polymeric scaffolds, but are advantageous in that they better match native tissue mechanical properties and have the potential to conform to individual injury anatomy. Biomaterial strategies for SCI can additionally support stem cell transplantation whether that is throughex vivo culture on a rigid scaffold (Dumont et al., 2018; Li et al., 2016; Mothe, Tam, Zahir, Tator, \& Shoichet, 2013), suspension in hydrogel injections (Assunção-Silva, Gomes, Sousa, Silva, \& Salgado, 2015; Cai, Dewi, \& Heilshorn, 2015; Marquardt \& Heilshorn, 2016), or direct injection into an integrated implant (Ciciriello et al., 2020). Alone, biomaterials passively modify immune cell infiltration and inflammation, resulting in improved stem cell survival post-transplantation, but a more active role in immune modulation can be taken through delivery of an anti-inflammatory factor.

Lentiviral vectors are a highly effective method for active therapeutic treatment with presently ongoing clinical trials (Milone \& O'Doherty, 2018). Lentivirus-mediated therapies work by integrating within a host genome, resulting in long-term overexpression of the selected gene of interest. Implantable biomaterials can serve as a medium for loading and release of lentivirus, and this has been investigated heavily in both SCI models (Abdellatif et al., 2006; Boehler et al., 2014; Daniel J. Margul et al., 2016; Park, Decker, Margul, et al., 2018; Park, Decker, Smith, et al., 2018; Dominique R. Smith et al., 2020; D. R. Smith et al., 2019) and for other tissue engineering applications like islet transplantation (Chou \& Sytwu, 2009; Jimenez-Moreno et al., 2015; J. M. H. Liu, Zhang, Joe, Luo, \& Shea, 2018), cancer immunotherapies (Arce, Breckpot, Collins, \& Escors, 2011; Liechtenstein, Perez-Janices, \& Escors, 2013; Milone \& O'Doherty, 2018), and cardiac tissue repair (Di Pasquale, Latronico, Jotti, \& Condorelli, 2012; Niwano et al., 2008; Zhao et al., 2002). Lentiviralmediated over-expression of cytokines from the IL family, specifically those targeting macrophages, has 
shown promise in altering immune response post-injury. Macrophages are a well-studied cell population, often viewed as an attractive therapeutic target. Infiltrating macrophages are traditionally grouped into two general phenotype classes, pro-inflammatory M1 and pro-regenerative M2, each with important functions post-injury. In reality, the behavior of these phenotypes is much more nuanced than the binary options presented here (Mosser \& Edwards, 2008), but this provides a frame of reference for distinguishing between pro-inflammatory and pro-regenerative roles. Furthermore, this described phenotypic difference opens the opportunity for lentiviral-mediated overexpression of an anti-inflammatory cytokine, like IL-10, to facilitate the polarization of M1 to M2 macrophages to create a more pro-regenerative microenvironment.

In this work, we expand the passive microenvironment modulation of our macroporous PEG tubes to actively modify the transplantation microenvironment through lentiviral-mediated delivery of IL-10. Previously, we demonstrated the short-term feasibility of the temporally flexible transplantation of enhanced green fluorescent protein $\left(\mathrm{EGFP}^{+}\right)$embryonic day 14 (E14) spinal progenitors into integrated PEG tubes (Ciciriello et al., 2020). Expanding on this prior work, in our current study we will implant IL-10 encoding lentivirus-laden tubes into a C5 lateral hemisection, and two weeks later inject $\mathrm{EGFP}^{+} \mathrm{E} 14$ spinal progenitors directly into the tubes at the lesion epicenter. This two week period between tube implantation and E14 spinal progenitor transplantation affords the tubes time to integrate and the IL-10 encoding lentivirus to modulate the immune response, ultimately improving transplantation. Alone, the tubes served as a privileged cell transplantation site, so we anticipate that adding lentivirus-mediated IL-10 delivery will further improve transplantation survival, resulting in long term benefits in regeneration and functional restoration through both endogenous and exogenous repair mechanisms, marking an important step forward in the development of a comprehensive cell delivery platform for SCI repair.

Methods

Fabrication of hydrogel tubes

Hydrogel tubes were generated as previously described (Dumont et al., 2019). Briefly, 20\% w/v 8-arm polyethylene glycol maleimide (PEG-MAL, $20 \mathrm{kDa}$; JenKem, Plano, TX) was crosslinked with $5 \mathrm{mM}$ slowdegrading-plasmin-sensitive YKND cross-linking peptide (Ac-GCYKNDGCYKNDCG; Genscript, Piscataway, NJ) (Shikanov, Smith, Xu, Woodruff, \& Shea, 2011) to form microspheres through water-oil emulsion with diameter ranging between 15 and $150 \mu \mathrm{m}$ and an average of $45 \mu \mathrm{m}$. The PEG-YKND solution was homogenized in silicone oil (Fisher, Hampton, NH) with 2\% Tween-20 (Sigma, St. Louis, MO) at a speed of $4000 \mathrm{rpm}$ for 1 minute. Microspheres were rinsed by centrifugation three times. Irgacure 2959 photoinitiator (Sigma) dissolved in N-vinylpyrrolidinone $(660 \mathrm{mg} / \mathrm{mL}$; Sigma) was added to the microspheres at a final concentration of $1 \% \mathrm{w} / \mathrm{v}$. The resulting microspheres were then packed into polydimethylsiloxane (PDMS, Dow Corning, Midland, MI) molds to generate PEG tubes (approximate OD: $600 \mu \mathrm{m}$, ID: $250 \mu \mathrm{m}$, porosity $66 \%)$ and exposed to an ultraviolet lamp for 3 minutes to initiate free radical polymerization. Tubes were rinsed three times, dehydrated, and stored at -80 until use. Tubes were cut to length during surgery to ensure fit within the defect.

Spinal progenitor isolation

All animal work pertaining to progenitor cell isolation was performed with prior approval and in accordance with the Institutional Animal Care and Use Committee (IACUC) guidelines at the University of Michigan and University of Miami. Embryonic spinal progenitors were isolated from the spinal cords of embryonic day 14 (E14) C57BL/6-Tg(CAG-EGFP)10sb/J mice (Jackson Laboratory, Bar Harbor, ME), enzymatically dissociated with $10 \mathrm{U} / \mathrm{mL}$ papain (Worthington, Lakewood, NY) and $37 \mu \mathrm{g} / \mathrm{mL}$ DNase (Sigma) into single cells, and expanded as neurospheres in ultralow attachment flasks (Corning, Corning, NY), as described previously (Dumont et al., 2018). Embryonic spinal progenitors were expanded in Dulbecco's Modified Eagle Medium (DMEM; Gibco, Grand Island, NY) supplemented with 1X B27 (Gibco), 1X N2 (Gibco), $\mathrm{N}$-acetyl cysteine (NAC; Sigma), and $20 \mathrm{ng} / \mathrm{mL}$ basic fibroblast growth factor (FGF2; Peprotech, Rocky Hill, NJ) and leukemia inhibitory factor (LIF; Peprotech). E14 cell colonies were passaged with papain as needed and not used beyond the second passage for transplantation studies. 


\section{Production of lentiviral vectors}

Lentivirus was produced as described previously (D. R. Smith et al., 2019). HEK-293FT cells (80-90\% confluent, American Type Culture Collection, Manassas, VA) were transfected with third generation lentiviral packaging vectors and pLenti-CMV-Luciferase or pLenti-CMV-hIL10. Correct insertion was validated via DNA sequencing. Plasmids were incubated in OptiMEM (Life Technologies, Carlsbad, CA) with Lipofectamine 2000 (Life Technologies) for 20 minutes prior to being added to cells. After 48 hours of incubation, supernatant was collected, centrifuged to remove cellular debris, and then incubated with PEG-It (System Biosciences, Palo Alto, CA) for $16-24$ hours at $4^{\circ} \mathrm{C}$. Virus was centrifuged at $1500 \mathrm{~g}$ at $4^{\circ} \mathrm{C}$ for $30 \mathrm{~min}$, supernatant was removed, and the pellet was re-suspended in sterile phosphate buffered saline (PBS; Life Technologies). Viral solution was aliquoted and frozen at $-80^{\circ} \mathrm{C}$ until use. Viral titers used throughout the study were $4 \mathrm{E} 9 \mathrm{IU} / \mathrm{mL}$ as determined by the Lentivirus qPCR Titer Kit (Applied Biological Materials, Richmond, BC, Canada). Viral vectors used in this study were from the same batch as described by Smith et. al. (Dominique R. Smith et al., 2020), thus all in vivo protein expression data would be comparable between these studies. However, it should be noted that additional vector expression analysis was performed using the In Vivo Imaging System (IVIS; Perkin Elmer, Waltham, MA) with the pLenti-CMV-Luciferase vector as described below.

\section{SCI surgeries}

All animal work was performed with prior approval and in accordance with the Institutional Animal Care and Use Committee (IACUC) guidelines at the University of Michigan. A C5 lateral hemisection SCI was created in adult C57BL/6J female mice aged 6-8 weeks, as previously described (D. J. Margul et al., 2016; Thomas et al., 2013; Thomas et al., 2014). Briefly, mice were anesthetized with $2 \%$ isoflurane and provided preemptive local pain management (1 $\mathrm{mg} / \mathrm{kg}$ bupivacaine). After confirmation of anesthesia via toe pinch, a $2 \mathrm{~cm}$ incision was made in the skin to facilitate the laminectomy performed at C5. A $1.15 \mathrm{~mm}$ lateral hemisection was excised in the left side of the spinal cord. This ensures any functional deficits are confined to the left forepaw, providing an internal control with the right paw. PEG tubes were cut to size, allowed to dehydrate for $30 \mathrm{~s}$, and implanted individually into the injury site, which accommodated 5 tubes in total. A subset of these mice received $2 \mu \mathrm{L}$ of $4 \mathrm{E} 9 \mathrm{IU} / \mathrm{mL}$ pLenti-CMV-hIL10 viral vector injected directly into the tubes. Gelfoam was used to secure the injury site in all conditions, after which the muscles were sutured and skin stapled. A subset of mice (no-treatment control group) did not receive an implant but did receive gelfoam over the injured spinal cord. Mice were immediately provided post-operative antibiotics (enrofloxacin $2.5 \mathrm{mg} / \mathrm{kg}$ once a day for 2 weeks), analgesics $(0.1 \mathrm{mg} / \mathrm{kg}$ buprenorphine twice a day for 3 days), and supportive hydration $(1 \mathrm{~mL} / 20 \mathrm{~g}$ lactated ringer solution once a day for 5 days). Bladders were expressed twice daily until function recovered and staples were removed after 10 days. Surgical controls were put in place to limit lesion size variance, including the order of the incisions made to limit the effects of swelling to cut lines, measuring the distance between the rostral and caudal cuts, and verifying the absence of bruising to the contralateral tissue. Exclusion criteria include any deviations to the surgical controls, as well as any variance to the recovery timeline, including an inability to ambulate by post-operative day 3 . No mice met these exclusion criteria for this study.

All mice received a second surgery 14 days after the primary injury. Protocols for anesthesia and postoperative care were the same as described with the initial surgery. After anesthesia induction, an incision in the skin was made, sutures in the muscle were removed, and any remaining gelfoam was carefully removed from atop the spinal cord. Two injections of E14 EGFP spinal progenitors ( $2 \mu \mathrm{L}$ of 150,000 cells in PBS 300,000 cells/mouse) or PBS were injected in the rostral-medial and caudal-lateral regions of the hydrogel implant using a 33G $10 \mu \mathrm{L}$ Hamilton syringe at a rate of $1 \mu \mathrm{L} /$ minute. Gelfoam was placed back over the injury, muscles were sutured, and wound clips applied. Mice were euthanized and spinal cord segments (C4-6) were collected after 4 or 12 weeks (2 or 10 weeks after cell transplantation). For each condition, n $=4-12$ mice at each time point: $\mathrm{n}=4$ for histology at week $4(\mathrm{~N}=24), \mathrm{n}=6$ for bioluminescent imaging $(\mathrm{N}=12), \mathrm{n}=6$ for histology at week $12(\mathrm{~N}=36)$, and $\mathrm{n}=12$ for ladder beam analysis $(\mathrm{N}=72)$.

Bioluminescent imaging 
Bioluminescent signal was evaluated with IVIS. Mice used to assess bioluminescent signal received a single surgery, in which the injury was made, tubes were implanted, and $2 \mu \mathrm{L}$ of $4 \mathrm{E} 9 \mathrm{IU} / \mathrm{mL}$ lentivirus with a luciferase reporter was injected directly into the tubes. A second set of mice did not receive the viral injection and served as controls. Gelfoam was placed over the injury, muscles were sutured, and wound clips applied. After 7 days the wound clips were removed. Mice were injected with $150 \mathrm{mg} / \mathrm{kg}$ D-Luciferin (Promega, Madison, WI) intraperitoneally 10 minutes prior to imaging. Mice were sedated 5 minutes prior to imaging and transferred to the IVIS chamber under continuous isoflurane sedation. D-Luciferin injections and IVIS imaging were repeated at weeks 4, 6, 8, and 12. Living Image (Perkin Elmer) software was used to evaluate total flux based on bioluminescent signal within the injury site.

Endogenous progenitor identification

Bromodeoxyuridine (BrdU) was used to identify proliferating cells in the first 7 days post-SCI, as described previously (Ciciriello et al., 2020). Intraperitoneal injections of $50 \mathrm{mg} / \mathrm{kg}$ BrdU (Roche, Basel, Switzerland) were pulsed every day for 7 days, allowing 7 additional days for unbound BrdU to wash out before exogenous spinal progenitors were implanted, as done by others (Ciciriello et al., 2020; Z. Yang et al., 2015). Using this protocol, overlap of BrdU and exogenous EGFP cell transplants was not observed. Any cells that co-localized with BrdU and neuronal lineage markers described below were considered to arise from endogenous spinal progenitors giving rise to new cells along the neuronal lineage. Tissue sections requiring BrdU identification were first denatured in $2 \mathrm{~N} \mathrm{HCl}$ for 1 hour at $37{ }^{\circ} \mathrm{C}$ followed by neutralization in 2 five minute rinses of $0.1 \mathrm{M}$ borate buffer to facilitate antigen retrieval. Samples were incubated for 1 hour at room temperature in rat anti-BrdU (1:200, Abcam, Cambridge, UK) antibody followed by appropriate fluorophore-conjugated goat anti-rat secondary antibody before proceeding with additional immunohistochemistry of specific cell phenotypes described below.

Immunohistochemistry

Isolated spinal cords were flash frozen, and then cryosectioned transversely (4 or 12 week tissue) in $12 \mu \mathrm{m}$ sections. Immunohistochemistry analysis was performed using nine transverse sections evenly spaced across the rostral, middle, and caudal regions of the tubes and average across each animal allowing for comparisons between animals while considering regional differences (Ciciriello et al., 2020; Dumont et al., 2019). Samples were fixed, permeabilized (0.5\% triton-X for 10 minutes) and/or prepared with BrdU staining (described above) as necessary, and incubated overnight at $4^{\circ} \mathrm{C}$ with primary antibodies. The following antibodies were used for primary detection: rat anti-F4/80 (1:200, Abcam, Cambridge, United Kingdom), goat anti-arginase (1:100, Santa Cruz, Dallas, TX, USA), rabbit anti-neurofilament-200 (1:200, Sigma), goat anti-myelin basic protein (MBP; 1:500, Santa Cruz), chicken anti-P0 (1:250, Aves Labs, Tigard, OR), chicken anti-GFP (1:200, Aves Labs), rabbit anti-Tuj1 (1:500, Sigma), mouse anti-NeuN (1:500, Millipore, Burlington, MA), mouse anti-Nestin (1:200, Millipore), rabbit anti-GFAP (1:500, Thermo Scientific, Waltham, MA), and rat anti-IL10 (1:100, Thermo Scientific). Species-specific fluorescent secondary antibodies were used for detection at 1:1000 (Life Technologies, Carlsbad, CA, USA). Hoechst 33342 (Life Technologies) was used as a counterstain in all tissue sections. Immunostained tissue sections were imaged using an AxioObserver inverted fluorescent microscope (Zeiss, Oberkochen, Germany) using a 10X dry objective.

Progenitor survival, proliferation, and fate:Immunohistochemistry was used to verify no overlap between $\mathrm{BrdU}^{+}$and $\mathrm{EGFP}^{+}$cell types. Subpopulations of exogenous $\mathrm{EGFP}^{+}$cells and endogenous $\mathrm{BrdU}^{+}$cells were counted manually by two blinded researchers to evaluate progenitor-driven neurogenesis. The following cell populations were quantified: exogenous progenitors $\left(\mathrm{EGFP}^{+} \mathrm{BrdU}^{-} \mathrm{Nestin}^{+}\right)$, endogenous progenitors $\left(\mathrm{BrdU}^{+} \mathrm{EGFP}^{-} \mathrm{Nestin}^{+}\right)$, exogenous neuroblasts $\left(\mathrm{EGFP}^{+} \mathrm{BrdU}^{-} \mathrm{Nestin}^{+} \mathrm{Tuj}^{+}\right)$, endogenous neuroblasts $\left(\mathrm{BrdU}^{+} \mathrm{EGFP}^{-} \mathrm{Nestin}^{+} \mathrm{Tuj}^{+}\right)$, exogenous early neurons $\left(\mathrm{EGFP}^{+} \mathrm{BrdU}^{-} \mathrm{Tuj}^{+} \mathrm{Nestin}^{-}\right)$, endogenous early neurons $\left(\mathrm{BrdU}^{+} \mathrm{EGFP}^{-} \mathrm{Tuj}^{+} \mathrm{Nestin}^{-}\right)$, exogenous neurons $\left(\mathrm{EGFP}^{+} \mathrm{BrdU}^{-} \mathrm{NeuN}^{+}\right)$, and endogenous neurons $\left(\mathrm{BrdU}^{+} \mathrm{EGFP}^{-} \mathrm{NeuN}^{+}\right)$. Cells were quantified within the injury and normalized to the implant or injury (empty control) area. Nine tissues evenly distributed throughout the rostrocaudal axis of the injury were averaged for each animal. 
Axon Density and Myelination: Semi-automated counting software, previously described by McCreedy et al.(McCreedy et al., 2016), was used to quantify axons and the co-localization of myelin with axons in transverse sections Briefly, the software was calibrated using manual NF-200 ${ }^{+}$(axons), NF- $200^{+} \mathrm{MBP}^{+}$ (myelinated axons), and NF-200 ${ }^{+} \mathrm{MBP}^{+} \mathrm{P}^{+}$(Schwann cell myelinated axons) counts from a subset of transverse 10X images taken from different animals and regions of the implant. The software then used a series of Hessian filters and threshold functions within the bridge region to reduce noise for selected NF-200, MBP, and P0 images (McCreedy et al., 2016). The software then output total axon counts, as well as the myelinated axon counts based on the curvilinear MBP co-localizing with axons with or without P0 co-localization; image acquisition and analysis was performed by investigators blinded to treatment condition. ImageJ (NIH, Bethesda, MD, USA) was used to analyze all other fluorescent images and define the bridge area. Cells were quantified within the injury and normalized to the implant or injury (empty control) area. Nine tissues evenly distributed throughout the rostrocaudal axis of the injury were averaged for each animal.

Immune Cell Density and Glial Scar Thickness: Cells positive for $\mathrm{F} 4 / 80^{+}$(macrophages) and F4/80+ arginase $^{+}$(M2 macrophages) containing Hoechst ${ }^{+}$nuclei were counted manually by two blinded researchers to quantify macrophage infiltration. Additionally, researchers were blinded to condition during image acquisition and quantification to eliminate bias for all histological analyses. Cells were quantified within the injury and normalized to the implant or injury (empty control) area. Nine tissues evenly distributed throughout the rostrocaudal axis of the injury were averaged for each animal. Glial scar thickness was quantified via $\mathrm{GFAP}^{+}$staining at the injury as previously reported (Dumont et al., 2019). Reactive astrocytes strongly express GFAP when forming the glial scar post-injury. Two manual thickness measurements were averaged within each tissue, while nine tissues evenly distributed throughout the rostrocaudal axis of the injury were averaged for each animal.

\section{Locomotor assessment}

Ladder beam was used to evaluate mouse locomotor and coordination over a 12 week period post-SCI, as previously described for all conditions ( $\mathrm{N}=72,12$ per condition) (B. J. Cummings, Engesser-Cesar, Cadena, \& Anderson, 2007). Each of the 50 rungs were numbered and equally spaced along the length of the beam with a dark enclosure containing bedding at the far end of the apparatus. An HD Handycam camcorder (Sony, Tokyo, Japan) was used to record mouse ambulation across ladderbeam. Mice were acclimated to the ladder beam over three sessions in the two weeks preceding the initial surgery. Baseline scores were determined to separate animals into equal groups (tubes or gelfoam) prior to the initial surgery. Mice were evaluated on the ladder beam every 2 weeks over the course of the experiment. The 2 week evaluation occurred prior to the second surgery in which the mice received spinal progenitors or vehicle (PBS) injections. This was to allow researchers to separate animals in equal groups prior to the addition of cell transplants. Observation and ladder beam scoring were performed by two blinded observers for 3 trials per animal. Animals were scored by average forepaw full placement on the ladder beam during the task.

\section{Statistics}

Data normality was assessed using a Shapiro-Wilk normality test with an $\alpha$ value of 0.05 , which determined parametric statistical tests were appropriate for our analyses. Multiple comparison pairs were analyzed using a one-way or two-way ANOVA with Tukey post-hoc test. All statistics test significance using an $\alpha$ value of 0.05. For all graphs, ${ }^{*}$ denotes $\mathrm{p}<0.05,{ }^{* *}$ denotes $\mathrm{p}<0.01,{ }^{* * *}$ denotes $\mathrm{p}<0.005$, and ${ }^{* * * *}$ denotes $\mathrm{p}<$ 0.001 , unless otherwise specified in the figure caption. All values are reported as mean $+/$ - standard error of the mean (SEM). Prism 7 (GraphPad Software, La Jolla, CA) software was used for all data analysis.

1. Results

2. Lentiviral expression is sustained in PEG hydrogel tubes over 12 weeks A cohort of mice received a C5 lateral hemisection injury followed by immediate implantation of PEG hydrogel tubes with a subsequent injection of firefly luciferase (FLuc) encoding lentivirus directly into the tube. A subset of these mice did not receive lentiviral injections to serve as a background control. Bioluminescent signal from the FLuc reporter gene was measured over 12 weeks post-implantation to assess lentiviral 
expression. Lentiviral expression of FLuc was observed in the injured area (Fig. 1A ). The average bioluminescent signal was assessed across 12 weeks for mice receiving lentivirus and compared to those that did not receive lentivirus (Fig. 1B ). Increased FLuc expression was observed across the 12 weeks in lentivirus-laden PEG hydrogel tubes, with a significant increase observed at weeks 4,6 , and 8. These results matched lentiviral-mediated IL-10 presence at the injury demonstrated with immunohistochemistry (Fig. S1 ). IL-10 was strongly observed at 4 weeks post-injury in the tubes + IL-10 encoding lentivirus condition (Fig. S1A ), but there was a noticeable drop by 12 weeks (Fig. S1B ) that coincides with the decrease in signal measured via IVIS (Fig. 1B ). Conversely, no IL-10 was observed at 4 (Fig. S1C) or 12 weeks (Fig. S1D ) in the tubes alone condition.

3. Macrophage infiltration is not significantly changed among experimental groups This study included six total conditions tested, 3 without E14 spinal progenitors (SCI, tubes, tubes + IL-10) and 3 with E14 spinal progenitors (E14 only, E14 + tubes, E14 + tubes + IL-10). Each individual tube has an approximate inner diameter of $250 \mu \mathrm{m}$ and outer diameter of $600 \mu \mathrm{m}$ (Fig. S2A ). Upon implantation, the tubes integrate with surrounding tissue for two weeks prior to transplanting E14 spinal progenitors (Fig. S2B ). Four weeks following implantation tube lumens are visible when evaluating tissue sections transversely (Fig. S2C ), and immune cell infiltration was quantified through F4/80 staining for macrophages (Fig. 2A-F ). Identified F4/80+ macrophages were further classified through arginase staining where $\mathrm{F} 4 / 80^{+}$arginase $^{+}$macrophages were a pro-regenerative M2-like phenotype. No significant differences were observed in total (Fig. 2G ) or M2-specific (Fig. 2H ) macrophage density observed across all conditions at 4 weeks. M2 classified macrophages were then reported as a percent of total macrophages, and there were no significant differences observed in M2 fraction across all conditions (Fig. 2I ).

4. Implanted hydrogel tubes attenuate glial scar thickness

Four weeks post-tube implantation, a glial scar was observed in all conditions. The scar was quantified by measuring the thickness of the $\mathrm{GFAP}^{+}$astrocyte layer at the injury margin in transversely cross-section tissue (Fig. S3A ). Formation of the scar is important for remediating the integrity of the blood-brain barrier, but it can also act as a physical barrier limiting axon elongation into the injury site. Attenuation, rather than total ablation, of the glial scar can improve functional recovery. In all mice that received hydrogel tube implants (tubes, tubes + IL-10, E14 + tubes, E14 + tubes + IL-10) a significant decrease in average scar thickness at the medial interface was observed compared to both SCI only and E14 spinal progenitors only (Fig. S3B ).

E14 progenitor survival increases when combined with IL-10 encoding lentivirus loaded hydrogel tubes

Following hemisection injury, five tubes either loaded with IL-10 encoding lentivirus or empty, were implanted into the lesion. Additionally, an injury only condition with no tube implantation served as a control. These mice recovered for two weeks, at which point a second surgery was performed where mice were injected with two doses of 150,000 $\mathrm{EGFP}^{+}$E14 spinal progenitors or PBS as a control, delivered into the integrated tubes (Fig. 3A ). A subset of mice $(\mathrm{n}=4)$ were sacrificed after another two weeks (4 weeks post-injury) to assess the short-term survival of transplanted E14 spinal progenitors. EGFP ${ }^{+}$cells were observed in all conditions receiving transplants (Fig. 3B-D ). Survival was assessed as both a density normalized to the injury area and as a percent of transplanted cells. E14 spinal progenitor transplantation alone resulted in the lowest density $\left(20.3 \pm 7.5\right.$ cells $\left./ \mathrm{mm}^{2}\right)$ compared to E14 spinal progenitor transplants with tubes $(44.1 \pm$ 3.7 cells $\left./ \mathrm{mm}^{2}\right)$ and tubes with IL-10 encoding lentivirus $\left(67.2 \pm 19\right.$ cells $\left./ \mathrm{mm}^{2}\right)$ (Fig. 3E $)$. Similarly, mice receiving E14 spinal progenitor transplants with no additional treatments resulted in $0.7 \%$ of cells surviving, and those with transplants directly into tubes had 4.3\% survival. When the E14 spinal progenitors were transplanted into IL-10 lentivirus loaded tubes, cell survival increased to 8.1\%, an 11.5-fold increase over the E14 spinal progenitor alone condition (Fig. 3F ).

Implanted tubes support exogenous-sourced mature neuron formation by 12 weeks

Surviving transplanted E14 spinal progenitor commitment to a neuronal lineage was assessed at both 4 and 12 weeks post-injury. At 4 weeks post-injury (Fig. S4A-D ), no significant differences were observed 
in exogenous progenitor $\left(\mathrm{EGFP}^{+} \mathrm{Nestin}^{+}\right)$or neuroblast $\left(\mathrm{EGFP}^{+} \mathrm{Nestin}^{+} \mathrm{Tuj}^{+}\right)$densities $($Fig. S4E-F $)$, but there was a significant increase in exogenous-sourced immature neurons $\left(\mathrm{EGFP}^{+} \mathrm{Nestin}^{-} \mathrm{Tuj}^{+}\right.$) in mice receiving E14 spinal progenitor transplants into tubes (Fig. S4G ). No significant differences were observed in mature neuron formation $\left(\mathrm{EGFP}^{+} \mathrm{NeuN}^{+}\right)$at this early time point (Fig. S4H ). Similarly, endogenous progenitors were quantified at 4 weeks post-injury. To label endogenous progenitors, BrdU was injected for 7 days post-injury, followed by 7 days with no injections to allow sufficient clearance of BrdU prior to exogenous E14 spinal progenitor transplantation. Endogenous progenitor $\left(\mathrm{BrdU}^{+} \mathrm{Nestin}^{+}\right)$(Fig. S5A ), neuroblast $\left(\mathrm{BrdU}^{+} \mathrm{Nestin}^{+} \mathrm{Tuj}^{+}\right)$(Fig. S5B $)$, immature neuron $\left(\mathrm{BrdU}^{+} \mathrm{Nestin}^{-} \mathrm{Tuj} 1^{+}\right)($Fig. S5C $)$, and mature neuron $\left(\mathrm{BrdU}^{+} \mathrm{NeuN}^{+}\right)$(Fig. S5D ) densities had no significant differences across all conditions (Fig. S5E-H ).

Neuron formation at 12 weeks post-injury was assessed from both exogenous and endogenous progenitor cells (Fig. 4A ). For the conditions receiving transplanted $\mathrm{EGFP}^{+}$E14 spinal progenitors, neurons were identified as $\mathrm{EGFP}^{+} \mathrm{NeuN}^{+}$cells and quantified as a density normalized to the injury cross section and as a percent of total $\mathrm{EGFP}^{+}$positive cells. No significant differences were observed in $\mathrm{EGFP}^{+} \mathrm{NeuN}^{+}$densities between E14 spinal progenitors only $\left(0.12 \pm 0.1\right.$ cells $\left./ \mathrm{mm}^{2}\right)$, tubes with E14 spinal progenitors $(1.7 \pm 0.4$ cells $\left./ \mathrm{mm}^{2}\right)$, and IL-10 lentivirus loaded tubes with E14 spinal progenitors $\left(1.9 \pm 0.8\right.$ cells $\left./ \mathrm{mm}^{2}\right)(\mathbf{F i g}$. 4B ). When expressed as a percent of the total $\mathrm{EGFP}^{+}$cells mice receiving transplanted E14 spinal progenitors only had on average $12.8 \pm 10 \%$ of their transplants form neurons. This was significantly lower than the average percentages for mice receiving E14 spinal progenitors with blank tubes $(38.9 \pm 5.1 \%)$ and with IL-10 lentivirus loaded tubes $(44.3 \pm 1.7 \%)$ (Fig. 4C ). Endogenous-derived neurons were assessed as a density, and there were no significant differences across any of the conditions tested (Fig. 4D ).

Axon elongation increases with IL-10 lentivirus-laden hydrogel tubes and E14 spinal progenitors

Transverse cross sections of isolated spinal cords were evaluated to assess axon elongation in the lesion space at 12 weeks post-injury. Facilitating and encouraging axon elongation through the injury is crucial for any SCI treatment. Axon counts quantified using NF-200 staining were normalized to the injury area (Fig. S6 ), shown as the solid white border (Fig. 5A-F ) to give an axon density for each condition. Assessed samples were evenly spaced across rostral, middle, and caudal regions of the injuries and averaged as no significant differences in axon density were observed between individual regions within each condition. All conditions exhibited axon elongation into the injury (Fig. 5A-F ) at 12 weeks. Infiltrating axons were typically observed growing in fascicle-like bundles (Fig. 5G ) or as individual, elongated structures (Fig. $\mathbf{5 H}$ ). Mice receiving IL-10 lentivirus loaded tubes with E14 spinal progenitors had significantly greater axon formation (490 \pm 41 axons $/ \mathrm{mm}^{2}$ ) compared to all other conditions. No other significant differences were observed between conditions at this time point (Fig. 5I ).

Axon remyelination increases with E14 spinal progenitor delivery

Elongated axons were further characterized 12 weeks post-injury by the extent and source of their myelination to indicate functional axonal regrowth. Myelination was quantified as a density of $\mathrm{NF}-200^{+} \mathrm{MBP}^{+}$axons normalized to the injury area of a transverse cross section (Fig. S6 ). Mice not receiving tubes (SCI only and E14 only) exhibited a decreased cross-sectional area compared to the other conditions, most likely due to tissue collapse with no support from the implanted biomaterial. All conditions had myelinated axons present in the injury (Fig. 6A-F ). Mice receiving IL-10 lentivirus loaded tubes with E14 spinal progenitors had $83 \pm$ 13 myelinated axons $/ \mathrm{mm}^{2}$ which was a significantly greater density compared to the injury only control $(24 \pm$ 6 myelinated axons $/ \mathrm{mm}^{2}$ ), but they were not different compared to any of the other experimental conditions. Similarly, the E14 spinal progenitor only condition had a significant increase in myelin density $(105 \pm 12$ myelinated axons $/ \mathrm{mm}^{2}$ ) compared to the injury only but not any of the other conditions (Fig. 6G ). It is possible that the density calculations for the E14 spinal progenitor only condition are artificially inflated as a result of lower ipsilateral tissue area to normalize to, which might be attributable to tissue collapse with no biomaterial. Ipsilateral tissue in the E14 spinal progenitor only condition was approximately $67 \%, 70 \%$, and $39 \%$ lower by comparison to tubes + IL-10, E14 + tubes, and E14 + tubes + IL-10, respectively (Fig. S6 ). The percent of regenerated axons was determined by normalizing the number of $\mathrm{NF}-200^{+} \mathrm{MBP}^{+}$axons 
to the total number of NF-200 ${ }^{+}$axons and reported as a percent. Mice receiving E14 spinal progenitors had a significant increase in myelination percent compared to all other conditions tested, with $42 \pm 3 \%$ of their axons having myelin. No other significant differences were observed for myelination percent (Fig. $\mathbf{6 H}$ ).

Myelination source was determined where axons expressing $\mathrm{MBP}^{+} \mathrm{P}^{+}$were identified as Schwann cellderived myelinated axons and $\mathrm{MBP}^{+} \mathrm{P}^{-}$were assumed to be oligodendrocyte-derived. Both longitudinally and transversely myelinated axons were observed in the tissue (Fig. S7A ). Mice receiving E14 spinal progenitors alone and delivered into tubes had significant increases in Schwann cell-derived myelinated axon densities compared to the injury only control (Fig. S7B ). The percent of Schwann cell-derived myelinated axons was determined by normalizing the NF- $200^{+} \mathrm{MBP}^{+} \mathrm{P} 0^{+}$axons to all $\mathrm{NF}-200^{+} \mathrm{MBP}^{+}$axons and reported as a percent. The E14 spinal progenitor only condition had a significant increase in Schwann-cell derived myelin compared to all other conditions with $31 \pm 4 \%$ of axons coming from Schwann cells (Fig. S7C ). No other significant differences were observed.

\section{IL-10 lentivirus loaded tubes with E14 spinal progenitors increase rate of functional recovery}

The horizontal ladder beam test assessed the functional recovery of the left forelimb of mice at 2, 4, 8 , and 12 weeks post-injury. An average left paw placement score out of 50 possible rungs was assessed at each time point for each condition (Fig. 7 ). At 4 weeks post-injury the mice receiving IL-10 lentivirus loaded tubes and E14 spinal progenitors exhibited increased function compared to the injury only control. By 8 weeks, any combination of condition where the mice had tubes implanted demonstrated increased function, and at 12 weeks, all conditions had significantly more successful placements compared to the injury only control.

\section{Discussion}

Biomaterial-based strategies are increasingly relevant in SCI tissue engineering with numerous clinical trials investigating scaffold-based therapies (Tsintou, Dalamagkas, \& Seifalian, 2015). As a singular therapy, biomaterial implants can promote endogenous repair mechanisms and modulate immune responses, but combination therapies involving biomaterials, stem cells, and therapeutic factors are more effective as they can have therapeutic synergism, improving the potential to facilitate repair (Ashammakhi et al., 2019). In this work, we modified our PEG hydrogel tube platform to incorporate lentiviral-mediated anti-inflammatory overexpression while also serving as a soft substrate for delayed E14 spinal progenitor transplantation. Alone, the PEG tubes are soft enough to conform to injury anatomy while maintaining an aligned structure for axonal elongation guidance in an acute SCI (Dumont et al., 2019). Once implanted, the tubes create a more pro-regenerative environment, serving as a privileged injection site for E14 spinal progenitors 2 weeks after injury. Our previous work showed that transplanted cell survival is enhanced when injected into the tubes, compared to direct transplantation into the injury, demonstrating the feasibility of using this as a cell-biomaterial system for SCI (Ciciriello et al., 2020). While survival did improve with the integrated tubes, the stem cell-influenced results of that study were minimized as functional and histological assessments occurred only 2 weeks after cell transplantation (4 weeks after injury). Axon elongation and myelination were comparable between the tubes only and tubes with E14 spinal progenitor conditions indicating the tubes played a bigger role at this early time point. For the work presented here, we hypothesized that adding lentivirus encoding for the anti-inflammatory cytokine IL-10 to our implanted tubes would allow for active immune modulation to complement the immunomodulatory properties of the integrated tubes, further remediating the cell transplantation site. Herein we developed a combinatorial therapy that both improved cell transplantation survival while also exhibiting synergistic regenerative gains at 12 weeks post-injury in an acute cervical SCI.

Lentiviral-mediated therapies present an attractive option for local therapeutic delivery as the virus genome integrates into the host genome and gene-of-interest expression is sustained over long periods of time (Sakuma, Barry, \& Ikeda, 2012). Moreover, lentivirus can easily be loaded onto a biomaterial scaffold that can be implanted directly at an injury site (Avilés \& Shea, 2011; Shin, Salvay, \& Shea, 2010). For this work, we added lentivirus encoding the gene for the anti-inflammatory cytokine IL-10 to our hydrogel PEG tubes once implanted in an acute cervical SCI model. Previous reports have similarly used lentiviral delivery of anti- 
inflammatory cytokines from multi-channel poly(lactide-co -glycolide) (PLG) bridges in SCI models (Park, Decker, Margul, et al., 2018; Park, Decker, Smith, et al., 2018; Dominique R. Smith et al., 2020; D. R. Smith et al., 2019). In these studies, rigid PLG bridges were loaded with multiple rounds of virus ex vivo prior to implantation. Bridges loaded with IL-10 lentivirus significantly increased M2 macrophage phenotype density in the injured region compared to control conditions demonstrating the efficacy of lentiviral-mediated IL-10 overexpression in facilitating a shift towards a more pro-regenerative microenvironment. For our study, we injected IL-10 encoding lentivirus directly into our tubes immediately after implantation to modulate the immune response after injury and create a more hospitable microenvironment for transplanting E14 spinal progenitors two weeks later. Macrophage phenotype was assessed four weeks post-injury, and no significant differences across all conditions were observed for total macrophage density or M2 macrophage density and fraction. It should be noted that mice receiving IL-10 lentivirus injections did have a trending increase in M2 density and fraction. Other work with IL-10 lentivirus biomaterials has shown that the elevated M2 concentrations begin to resolve by 4 weeks post-injury, indicating an earlier assessment point for our work would likely show a significant increase in M2 density (Park, Decker, Margul, et al., 2018). Additionally, our viral load was lower by comparison to the dose used with rigid PLG bridges. Park et al. loaded their bridges with $2 \mu \mathrm{L}$ of $2 \mathrm{E} 9 \mathrm{IU} / \mathrm{mL}$ of virus and incubating for 2 minutes to allow it to absorb. This process was repeated three additional times for four total doses (Park, Decker, Margul, et al., 2018; Park, Decker, Smith, et al., 2018). By comparison, our viral loading conditions were somewhat restricted, as the tubes are dried prior to implantation for handling ease, and upon implantation, they swell to fit an injury. As a result, we could not load the tubes with virus ex vivo prior to implanting, potentially limiting the total viral load absorbed by the bridge. Loading concentrations were restricted to a single $2 \mu \mathrm{L}$ dose of $4 \mathrm{E} 9 \mathrm{IU} / \mathrm{mL}$, half of the total dose used by Park et al. Moving forward, viral loading concentrations and conditions will need to be optimized in order to observe a greater anti-inflammatory effect when used in conjunction with stem cell transplants. Furthermore, affinity peptides for the lentivirus can be incorporated into the hydrogel tubes to improve their retention and localization at the injury (Skoumal, Seidlits, Shin, \& Shea, 2016).

Stem cell transplantation into the injured spinal cord is a treatment option with high potential but has clinically been met with difficulty in cell sourcing and scale-up (Anderson, Piltti, Hooshmand, Nishi, \& Cummings, 2017; Levi et al., 2018; Temple \& Studer, 2017). In research, another notable barrier is low survival post-transplantation, which can largely be attributed to a cytotoxic transplantation site at the injury. As the post-injury immune response clears out dead cells and debris, it also targets transplanted cells, limiting their durability and potential to promote repair (Pereira, Marote, Salgado, \& Silva, 2019). Improving exogenous cell transplant survival would allow spinal progenitors to integrate with endogenous circuitry (Lien, Tuszynski, \& Lu, 2019; Paul Lu et al., 2017; Paul Lu et al., 2019) and remediate extracellular space (Hawryluk et al., 2012; P. Lu et al., 2003). Biomaterial strategies have long proven to be effective vehicles for transplanting stem cells to central nervous system (CNS) injuries as they can be functionalized for cell adhesion and offer a protective role against transplantation conditions (Higuchi et al., 2019; Katoh, Yokota, \& Fehlings, 2019). Bulk biomaterial implants, like porous PLG bridges (Dumont et al., 2018) or 3D printed scaffolds (Koffler et al., 2019), can be cultured ex vivo with stem cells and implanted into the injury. Rigid implants with a defined architecture also provide directional cues for axon elongation once in the injury. Alternatively, cells can be suspended in synthetic (Marquardt et al., 2020) or natural (Cerqueira et al., 2018; Mothe et al., 2013) hydrogels that are soft enough to be injected and form a biomimetic extracellular matrix once in the injury. Soft hydrogel implants are advantageous as they better mimic the mechanical properties of the surrounding native tissue and can swell to fit unique injury shapes, advancing their translatability.

Unfortunately, both ex vivo culturing and hydrogel suspension techniques for cell transplantation offer little control over delivery time relative to biomaterial implantation as cell transplants are dependent on the biomaterial as a carrier. The temporal dependence on the biomaterial limits the opportunity for addressing regenerative barriers, such as inflammation, prior to cell transplantation. Alternatively, stem cells can be directly injected into a previously implanted biomaterial that has had time to integrate and modulate the immune response. In our previous report we saw approximately $4.3 \%$ of transplanted E14 spinal progenitors survive two weeks after transplantation when injected into integrated PEG tubes (Ciciriello et al., 2020). 
For the present study, we similarly delayed E14 spinal progenitor transplantation for 2 weeks, but we additionally incorporated IL-10 encoding lentivirus to our PEG tubes at implantation. A buffer period between 1 and 2 weeks is common in SCI-cell transplant strategies (Brian J. Cummings et al., 2005; Führmann et al., 2016; Mothe et al., 2013), and we chose 2 weeks for delaying E14 spinal progenitor delivery to coincide with IL-10 lentivirus-attributable M2 polarization shown by others (Park, Decker, Margul, et al., 2018). Transplant survival was assessed after another 2 weeks, 4 weeks after tube implantation, and $8.1 \%$ of E14 spinal progenitors transplanted into IL-10 lentivirus loaded tubes survived, an 11.5-fold difference compared to the transplantation only control in this study. The $8.1 \%$ survival for the E14 spinal progenitors presented here is a significant increase in transplant engraftment compared to what has previously been demonstrated in immunocompetent models (Tejeda, Ciciriello, \& Dumont, 2021). Combining the independent immunomodulatory properties of the tubes with lentiviral-mediated overexpression of IL-10 resulted in synergistic gains for the transplants, significantly improving their survival.

Exogenous NSC transplants can facilitate de novo neurogenesis, improving regenerative potential post-SCI (Ogawa et al., 2002). We assessed neurogenesis from surviving exogenous E14 spinal progenitors at both 4 and 12 weeks post-injury ( 2 and 10 weeks post-transplantation, respectively) using NeuN staining, a marker for mature neuron formation. At 4 weeks post-injury, very little staining was observed for $\mathrm{EGFP}^{+} \mathrm{NeuN}^{+}$cells, indicating low levels of neurogenesis from exogenous cells, however an observable increase in neuronal lineage commitment was observed with Tuj staining in $\mathrm{EGFP}^{+}$cells transplanted with tubes or IL-10 lentivirusladen tubes. Ogawa et al., transplanted E14.5 spinal progenitors 9 days after a contusive injury, and they observed neurogenesis beginning at 5 weeks post-transplantation, albeit in a rat model (Ogawa et al., 2002), so it is unsurprising that we saw few mature neurons at our earlier time point. By 12 weeks post-injury, we did observe an increase in NeuN staining densities across conditions with a significant increase in the percentage of $\mathrm{EGFP}^{+}$cells co-staining for $\mathrm{NeuN}^{+}$cells observed in conditions that received tube implants.

In a hemisection injury model, as used in the present study, all tissue on the ipsilateral side of the injury is completely removed, thus any axons identified histologically are attributable to post-injury regrowth. Increasing axon density and elongation is an important factor when designing a treatment for SCI as this will bridge the healthy tissue rostral and caudal to the injury. Additionally, remyelination of these new axons is important for signal propagation along axons in the CNS, a process that is largely attributed to the myelin sheath. We observed a significantly higher axon density at the injury in mice receiving IL-10 lentivirus loaded tubes with E14 spinal progenitors compared to all other experimental conditions. With that in mind, it should be noted that sparing, plasticity, axonal growth, and remyelination likely occurred early after implantation and transplantation. It is suspected that by 12 weeks post-injury the anti-inflammatory effects of the tubes and E14 spinal progenitors have resolved. Benefits from the tubes and E14 spinal progenitors are known to have an early impact as we previously saw in mice with E14 spinal progenitors alone, tubes alone, and tubes with E14 spinal progenitors had increased axonal densities and myelinated axon densities at 4 weeks post-injury (Ciciriello et al., 2020). In this study, mice receiving E14 spinal progenitors with IL-10 lentivirus-laden tubes possibly had a longer therapeutic regime compared to all other conditions, resulting in the significant increase in axon density. Directly comparing densities between conditions can be misleading if the overall context is not considered, and this is more apparent with the myelin data. The mice that received E14 spinal progenitors only had an average injury area of $1.10 \pm 0.5 \mathrm{~mm}^{2}$ compared to the expected area of $1.75 \mathrm{~mm}^{2}$ based on the cross-sectional area of resected tissue. These mice may have experienced some tissue collapse as there was no biomaterial to fill the lesion, effectively lowering the area to which cell counts are normalized and artificially inflating densities. Axonal remyelination results in the E14 spinal progenitor only condition indicate they had significantly improved remyelination compared to other conditions, but this might be attributable to a lower cross-sectional area resulting in a higher apparent density. This discrepancy is also highlighted when comparing axon myelination to functional data. The E14 only condition had the most myelin of all the conditions, but it was the last treatment group to reach significantly more successful placements compared to the SCI only group. This disparity between histological and functional data raises a point of disconnect that could possibly be attributable to improper synapse formation or poor myelin quality, which could be investigated to better understand this relationship. 
Conclusion Stem cell transplantations are a promising therapy across tissue engineering, especially in CNS damage and disease. Unfortunately, therapeutic effect is minimized by poor survival resulting from poor flexibility in transplantation strategies, subjecting the cells to inhospitable conditions upon injection. Biomaterials and therapeutic factors can facilitate improved conditions, but they are often delivered simultaneously with cell transplants, limiting the perceived immunomodulatory effect on the cells. In this study, our hydrogel tube system affords temporal independence between cell transplantation and biomaterial implantation, an advantage absent in many other cell-biomaterial strategies. In addition to temporal independence, we enhanced the passive immunomodulatory properties of our hydrogel tube system with active immunomodulation via IL-10 encoding lentivirus release from the tubes. In a 2 week course of combined passive and active immunomodulation prior to transplantation, the IL-10 lentivirus loaded tubes effectively created a privileged cell transplantation site for E14 spinal progenitors. To that end, we observed a significant increase in transplant survival and axon elongation in addition to a more rapid functional recovery. Altogether, this therapy synergizes the therapeutic benefits of biomaterials, stem cells, and therapeutic factor delivery, representing a combinatorial approach capable of addressing several of the challenges that limit recovery post-SCI.

Supporting Information: Additional supporting information may be found in the online version of this article.

Figure S1: IL-10 expression at 4 and 12 weeks

Figure S2: PEG implants facilitate tissue ingrowth

Figure S3: Glial scarring is decreased in mice receiving tubes

Figure S4: Exogenous progenitor characterization at 4 weeks

Figure S5: Endogenous progenitor characterization at 4 weeks

Figure S6: Ipsilateral tissue area is lower in conditions not receiving PEG implants

Figure S7: Remyelinated axons have Schwann cell derived myelin

Data Availability: The datasets generated during and/or analyzed during the present study are available from the corresponding author upon reasonable request.

Conflict of Interest: The authors declare no conflicts of interest.

Author Contributions: Study design - AJC, DRS, LDS, CMD; Data collection - AJC, DRS, MKM, CMD; Data analysis - AJC, DRS, MKM, SJB, CMD; Manuscript drafting - AJC, CMD; Revising and approving final manuscript - AJC, DRS, MKM, SJB, LDS, CMD

\section{References}

Abdellatif, A. A., Pelt, J. L., Benton, R. L., Howard, R. M., Tsoulfas, P., Ping, P., . . Whittemore, S. R. (2006). Gene delivery to the spinal cord: comparison between lentiviral, adenoviral, and retroviral vector delivery systems. Journal of Neuroscience Research, 84 (3), 553-567. doi:10.1002/jnr.20968

Alizadeh, A., Dyck, S. M., \& Karimi-Abdolrezaee, S. (2019). Traumatic Spinal Cord Injury: An Overview of Pathophysiology, Models and Acute Injury Mechanisms. Frontiers in Neurology, 10 (282). doi:10.3389/fneur.2019.00282

Anderson, A. J., Piltti, K. M., Hooshmand, M. J., Nishi, R. A., \& Cummings, B. J. (2017). Preclinical Efficacy Failure of Human CNS-Derived Stem Cells for Use in the Pathway Study of Cervical Spinal Cord Injury. Stem Cell Reports, 8 (2), 249-263. doi:10.1016/j.stemcr.2016.12.018

Arce, F., Breckpot, K., Collins, M., \& Escors, D. (2011). Targeting lentiviral vectors for cancer immunotherapy. Current cancer therapy reviews, 7 (4), 248-260. doi:10.2174/157339411797642605 
Ashammakhi, N., Kim, H.-J., Ehsanipour, A., Bierman, R. D., Kaarela, O., Xue, C., . . . Seidlits, S. K. (2019). Regenerative Therapies for Spinal Cord Injury. Tissue Engineering Part B: Reviews, 25 (6), 471491. doi:10.1089/ten.teb.2019.0182

Assunção-Silva, R. C., Gomes, E. D., Sousa, N., Silva, N. A., \& Salgado, A. J. (2015). Hydrogels and Cell Based Therapies in Spinal Cord Injury Regeneration. Stem cells international, 2015 , 948040-948040. doi:10.1155/2015/948040

Avilés, M. O., \& Shea, L. D. (2011). Hydrogels to modulate lentivirus delivery in vivo from microporous tissue engineering scaffolds.Drug delivery and translational research, 1 (1), 91-101. doi:10.1007/s13346-010-0011-1

Boehler, R. M., Kuo, R., Shin, S., Goodman, A. G., Pilecki, M. A., Leonard, J. N., \& Shea, L. D. (2014). Lentivirus delivery of IL-10 to promote and sustain macrophage polarization towards an anti-inflammatory phenotype. Biotechnology and Bioengineering, 111 (6), 1210-1221. doi:10.1002/bit.25175

Bradbury, E. J., \& Burnside, E. R. (2019). Moving beyond the glial scar for spinal cord repair. Nature Communications, 10 (1), 3879. doi:10.1038/s41467-019-11707-7

Busch, S. A., Horn, K. P., Silver, D. J., \& Silver, J. (2009). Overcoming macrophage-mediated axonal dieback following CNS injury.Journal of Neuroscience, 29 (32), 9967-9976. doi:10.1523/JNEUROSCI.1151-09.2009

Cai, L., Dewi, R. E., \& Heilshorn, S. C. (2015). Injectable Hydrogels with In Situ Double Network Formation Enhance Retention of Transplanted Stem Cells. Advanced functional materials, 25 (9), 1344-1351. doi:10.1002/adfm.201403631

Cerqueira, S. R., Lee, Y.-S., Cornelison, R. C., Mertz, M. W., Wachs, R. A., Schmidt, C. E., \& Bunge, M. B. (2018). Decellularized peripheral nerve supports Schwann cell transplants and axon growth following spinal cord injury. Biomaterials, 177 , 176-185. doi:10.1016/j.biomaterials.2018.05.049

Ceto, S., Sekiguchi, K. J., Takashima, Y., Nimmerjahn, A., \& Tuszynski, M. H. (2020). Neural Stem Cell Grafts Form Extensive Synaptic Networks that Integrate with Host Circuits after Spinal Cord Injury. Cell stem cell . doi:10.1016/j.stem.2020.07.007

Chen, J., Bernreuther, C., Dihné, M., \& Schachner, M. (2005). Cell Adhesion Molecule L1-Transfected Embryonic Stem Cells with Enhanced Survival Support Regrowth of Corticospinal Tract Axons in Mice after Spinal Cord Injury. Journal of neurotrauma, 22 (8), 896-906. doi:10.1089/neu.2005.22.896

Cheng, Z., Zhu, W., Cao, K., Wu, F., Li, J., Wang, G., . . . He, X. (2016). Anti-Inflammatory Mechanism of Neural Stem Cell Transplantation in Spinal Cord Injury. International journal of molecular sciences, 17 (9), 1380. doi:10.3390/ijms17091380

Chou, F.-C., \& Sytwu, H.-K. (2009). Overexpression of thioredoxin in islets transduced by a lentiviral vector prolongs graft survival in autoimmune diabetic NOD mice. Journal of Biomedical Science, 16 (1), 71-71. doi:10.1186/1423-0127-16-71

Ciciriello, A. J., Smith, D. R., Munsell, M. K., Boyd, S. J., Shea, L. D., \& Dumont, C. M. (2020). Acute Implantation of Aligned Hydrogel Tubes Supports Delayed Spinal Progenitor Implantation. ACS Biomaterials Science \& Engineering, 6 (10), 5771-5784. doi:10.1021/acsbiomaterials.0c00844

Cummings, B. J., Engesser-Cesar, C., Cadena, G., \& Anderson, A. J. (2007). Adaptation of a ladder beam walking task to assess locomotor recovery in mice following spinal cord injury. Behav Brain Res, 177 (2), 232-241. doi:10.1016/j.bbr.2006.11.042

Cummings, B. J., Uchida, N., Tamaki, S. J., Salazar, D. L., Hooshmand, M., Summers, R., . . Anderson, A. J. (2005). Human neural stem cells differentiate and promote locomotor recovery in spinal cord-injured mice. Proceedings of the National Academy of Sciences of the United States of America, 102 (39), 14069. doi:10.1073/pnas.0507063102 
Dalamagkas, K., Tsintou, M., Seifalian, A., \& Seifalian, A. M. (2018). Translational Regenerative Therapies for Chronic Spinal Cord Injury.International journal of molecular sciences, 19 (6), 1776. doi:10.3390/ijms19061776

Di Pasquale, E., Latronico, M. V. G., Jotti, G. S., \& Condorelli, G. (2012). Lentiviral vectors and cardiovascular diseases: a genetic tool for manipulating cardiomyocyte differentiation and function. Gene Therapy, 19 (6), 642-648. doi:10.1038/gt.2012.19

Donnelly, D. J., \& Popovich, P. G. (2008). Inflammation and its role in neuroprotection, axonal regeneration and functional recovery after spinal cord injury. Experimental Neurology, 209 (2), 378-388. doi:10.1016/j.expneurol.2007.06.009

Dulin, J. N., \& Lu, P. (2014). Bridging the injured spinal cord with neural stem cells. Neural regeneration research, 9 (3), 229-231. doi:10.4103/1673-5374.128212

Dumont, C. M., Carlson, M. A., Munsell, M. K., Ciciriello, A. J., Strnadova, K., Park, J., . . Shea, L. D. (2019). Aligned hydrogel tubes guide regeneration following spinal cord injury. Acta Biomater, 86 , 312-322. doi:10.1016/j.actbio.2018.12.052

Dumont, C. M., Margul, D. J., \& Shea, L. D. (2016). Tissue Engineering Approaches to Modulate the Inflammatory Milieu following Spinal Cord Injury. Cells Tissues Organs, 202 (1-2), 52-66. doi:10.1159/000446646

Dumont, C. M., Munsell, M. K., Carlson, M. A., Cummings, B. J., Anderson, A. J., \& Shea, L. D. (2018). Spinal Progenitor-Laden Bridges Support Earlier Axon Regeneration Following Spinal Cord Injury.Tissue Eng Part A, 24 (21-22), 1588-1602. doi:10.1089/ten.TEA.2018.0053

Führmann, T., Tam, R. Y., Ballarin, B., Coles, B., Elliott Donaghue, I., van der Kooy, D., . . Shoichet, M. S. (2016). Injectable hydrogel promotes early survival of induced pluripotent stem cell-derived oligodendrocytes and attenuates longterm teratoma formation in a spinal cord injury model. Biomaterials, 83 , 23-36. doi:10.1016/j.biomaterials.2015.12.032

Hackett, A. R., \& Lee, J. K. (2016). Understanding the NG2 Glial Scar after Spinal Cord Injury. Frontiers in Neurology, 7 (199). doi:10.3389/fneur.2016.00199

Hall, E. D. (2011). Antioxidant therapies for acute spinal cord injury.Neurotherapeutics : the journal of the American Society for Experimental NeuroTherapeutics, 8 (2), 152-167. doi:10.1007/s13311-011-0026-4

Hawryluk, G. W. J., Mothe, A., Wang, J., Wang, S., Tator, C., \& Fehlings, M. G. (2012). An in vivo characterization of trophic factor production following neural precursor cell or bone marrow stromal cell transplantation for spinal cord injury. Stem Cells and Development, 21 (12), 2222-2238. doi:10.1089/scd.2011.0596

Higuchi, A., Suresh Kumar, S., Benelli, G., Ling, Q.-D., Li, H.-F., Alarfaj, A. A., . . Murugan, K. (2019). Biomaterials used in stem cell therapy for spinal cord injury. Progress in Materials Science, 103 , 374-424. doi:10.1016/j.pmatsci.2019.02.002

Hill, C. E. (2017). A view from the ending: Axonal dieback and regeneration following SCI. Neuroscience Letters, 652 , 11-24. doi:10.1016/j.neulet.2016.11.002

Jimenez-Moreno, C. M., Herrera-Gomez, I. d. G., Lopez-Noriega, L., Lorenzo, P. I., Cobo-Vuilleumier, N., Fuente-Martin, E., . . . Martin-Montalvo, A. (2015). A Simple High Efficiency Intra-Islet Transduction Protocol Using Lentiviral Vectors. Current gene therapy, 15 (4), 436-446. doi:10.2174/1566523215666150630121557

Karimi-Abdolrezaee, S., Eftekharpour, E., Wang, J., Morshead, C. M., \& Fehlings, M. G. (2006). Delayed Transplantation of Adult Neural Precursor Cells Promotes Remyelination and Functional Neurological Recovery after Spinal Cord Injury. The Journal of Neuroscience, 26 (13), 3377. doi:10.1523/JNEUROSCI.418405.2006

Katoh, H., Yokota, K., \& Fehlings, M. G. (2019). Regeneration of Spinal Cord Connectivity Through Stem Cell Transplantation and Biomaterial Scaffolds. Frontiers in cellular neuroscience, 13 , 248-248. 
doi:10.3389/fncel.2019.00248

Koffler, J., Zhu, W., Qu, X., Platoshyn, O., Dulin, J. N., Brock, J., . . Tuszynski, M. H. (2019). Biomimetic 3D-printed scaffolds for spinal cord injury repair. Nature medicine, 25 (2), 263-269. doi:10.1038/s41591-0180296-z

Kumamaru, H., Kadoya, K., Adler, A. F., Takashima, Y., Graham, L., Coppola, G., \& Tuszynski, M. H. (2018). Generation and post-injury integration of human spinal cord neural stem cells. Nature Methods, 15 (9), 723-731. doi:10.1038/s41592-018-0074-3

Kwon, S. G., Kwon, Y. W., Lee, T. W., Park, G. T., \& Kim, J. H. (2018). Recent advances in stem cell therapeutics and tissue engineering strategies. Biomaterials research, 22 , 36-36. doi:10.1186/s40824-0180148-4

Lacroix, S., Chang, L., Rose-John, S., \& Tuszynski, M. H. (2002). Delivery of hyper-interleukin-6 to the injured spinal cord increases neutrophil and macrophage infiltration and inhibits axonal growth.J Comp Neurol, 454 (3), 213-228. doi:10.1002/cne.10407

Levi, A. D., Anderson, K. D., Okonkwo, D. O., Park, P., Bryce, T. N., Kurpad, S. N., . . Gant, K. (2018). Clinical Outcomes from a Multi-Center Study of Human Neural Stem Cell Transplantation in Chronic Cervical Spinal Cord Injury. Journal of neurotrauma, 36 (6), 891-902. doi:10.1089/neu.2018.5843

Li, X., Liu, S., Zhao, Y., Li, J., Ding, W., Han, S., . . . Dai, J. (2016). Training Neural Stem Cells on Functional Collagen Scaffolds for Severe Spinal Cord Injury Repair. Advanced functional materials, 26 (32), 5835-5847. doi:10.1002/adfm.201601521

Liechtenstein, T., Perez-Janices, N., \& Escors, D. (2013). Lentiviral vectors for cancer immunotherapy and clinical applications. Cancers, 5 (3), 815-837. doi:10.3390/cancers5030815

Lien, B. V., Tuszynski, M. H., \& Lu, P. (2019). Astrocytes migrate from human neural stem cell grafts and functionally integrate into the injured rat spinal cord. Experimental Neurology, 314 , 46-57. doi:10.1016/j.expneurol.2019.01.006

Liu, J. M. H., Zhang, X., Joe, S., Luo, X., \& Shea, L. D. (2018). Evaluation of biomaterial scaffold delivery of IL-33 as a localized immunomodulatory agent to support cell transplantation in adipose tissue. Journal of Immunology and Regenerative Medicine, 1 , 1-12. doi:10.1016/j.regen.2018.01.003

Liu, S., Schackel, T., Weidner, N., \& Puttagunta, R. (2018). Biomaterial-Supported Cell Transplantation Treatments for Spinal Cord Injury: Challenges and Perspectives. Frontiers in cellular neuroscience, 11 (430). doi:10.3389/fncel.2017.00430

Liu, S., Xie, Y.-Y., \& Wang, B. (2019). Role and prospects of regenerative biomaterials in the repair of spinal cord injury.Neural regeneration research, 14 (8), 1352-1363. doi:10.4103/1673-5374.253512

Liu, X. Z., Xu, X. M., Hu, R., Du, C., Zhang, S. X., McDonald, J. W., . . Choi, D. W. (1997). Neuronal and glial apoptosis after traumatic spinal cord injury. The Journal of neuroscience : the official journal of the Society for Neuroscience, 17 (14), 5395-5406. doi:10.1523/JNEUROSCI.17-14-05395.1997

Lu, P., Ceto, S., Wang, Y., Graham, L., Wu, D., Kumamaru, H., . . . Tuszynski, M. H. (2017). Prolonged human neural stem cell maturation supports recovery in injured rodent CNS. The Journal of clinical investigation, 127 (9), 3287-3299. doi:10.1172/JCI92955

Lu, P., Gomes-Leal, W., Anil, S., Dobkins, G., Huie, J. R., Ferguson, A. R., . . Tuszynski, M. (2019). Origins of Neural Progenitor Cell-Derived Axons Projecting Caudally after Spinal Cord Injury.Stem Cell Reports, 13 (1), 105-114. doi:10.1016/j.stemcr.2019.05.011

Lu, P., Jones, L. L., Snyder, E. Y., \& Tuszynski, M. H. (2003). Neural stem cells constitutively secrete neurotrophic factors and promote extensive host axonal growth after spinal cord injury.Experimental Neurology, 181 (2), 115-129. doi:10.1016/S0014-4886(03)00037-2 
Margul, D. J., Park, J., Boehler, R. M., Smith, D. R., Johnson, M. A., McCreedy, D. A., . . Seidlits, S. K. (2016). Reducing neuroinflammation by delivery of IL-10 encoding lentivirus from multiple-channel bridges. Bioeng Transl Med, 1 (2), 136-148. doi:10.1002/btm2.10018

Margul, D. J., Park, J., Boehler, R. M., Smith, D. R., Johnson, M. A., McCreedy, D. A., . . Seidlits, S. K. (2016). Reducing neuroinflammation by delivery of IL-10 encoding lentivirus from multiple-channel bridges. Bioengineering \& Translational Medicine, 1 (2), 136-148. doi:10.1002/btm2.10018

Marquardt, L. M., Doulames, V. M., Wang, A. T., Dubbin, K., Suhar, R. A., Kratochvil, M. J., ... Heilshorn, S. C. (2020). Designer, injectable gels to prevent transplanted Schwann cell loss during spinal cord injury therapy. Science Advances, 6 (14), eaaz1039. doi:10.1126/sciadv.aaz1039

Marquardt, L. M., \& Heilshorn, S. C. (2016). Design of Injectable Materials to Improve Stem Cell Transplantation. Current stem cell reports, 2 (3), 207-220. doi:10.1007/s40778-016-0058-0

McCreedy, D. A., Margul, D. J., Seidlits, S. K., Antane, J. T., Thomas, R. J., Sissman, G. M., . . Shea, L. D. (2016). Semi-automated counting of axon regeneration in poly(lactide co-glycolide) spinal cord bridges. $J$ Neurosci Methods, 263 , 15-22. doi:10.1016/j.jneumeth.2016.01.021

Milone, M. C., \& O'Doherty, U. (2018). Clinical use of lentiviral vectors. Leukemia, 32 (7), 1529-1541. doi:10.1038/s41375-018-0106-0

Mortazavi, M. M., Jaber, M., Adeeb, N., Deep, A., Hose, N., Rezaei, M., . . Tubbs, R. S. (2015). Engraftment of neural stem cells in the treatment of spinal cord injury. Translational Research in Anatomy, 1 , 11-16. doi:10.1016/j.tria.2015.10.002

Mosser, D. M., \& Edwards, J. P. (2008). Exploring the full spectrum of macrophage activation. Nature reviews. Immunology, 8 (12), 958-969. doi:10.1038/nri2448

Mothe, A. J., Tam, R. Y., Zahir, T., Tator, C. H., \& Shoichet, M. S. (2013). Repair of the injured spinal cord by transplantation of neural stem cells in a hyaluronan-based hydrogel. Biomaterials, 34 (15), 3775-3783. doi:10.1016/j.biomaterials.2013.02.002

Nagoshi, N., Khazaei, M., Ahlfors, J.-E., Ahuja, C. S., Nori, S., Wang, J., . . . Fehlings, M. G. (2018). Human Spinal Oligodendrogenic Neural Progenitor Cells Promote Functional Recovery After Spinal Cord Injury by Axonal Remyelination and Tissue Sparing. Stem cells translational medicine, 7 (11), 806-818. doi:10.1002/sctm.17-0269

Niwano, K., Arai, M., Koitabashi, N., Watanabe, A., Ikeda, Y., Miyoshi, H., \& Kurabayashi, M. (2008). Lentiviral Vector\&\#x2013;mediated $<\mathrm{em}>$ SERCA2 $</$ em $>$ Gene Transfer Protects Against Heart Failure and Left Ventricular Remodeling After Myocardial Infarction in Rats. Molecular Therapy, 16 (6), 1026-1032. doi:10.1038/mt.2008.61

Ogawa, Y., Sawamoto, K., Miyata, T., Miyao, S., Watanabe, M., Nakamura, M., . . . Okano, H. (2002). Transplantation of in vitro-expanded fetal neural progenitor cells results in neurogenesis and functional recovery after spinal cord contusion injury in adult rats. Journal of Neuroscience Research, 69 (6), 925-933. doi:10.1002/jnr.10341

Park, J., Decker, J. T., Margul, D. J., Smith, D. R., Cummings, B. J., Anderson, A. J., \& Shea, L. D. (2018). Local Immunomodulation with Anti-inflammatory Cytokine-Encoding Lentivirus Enhances Functional Recovery after Spinal Cord Injury. Molecular Therapy, 26 (7), 1756-1770. doi:10.1016/j.ymthe.2018.04.022

Park, J., Decker, J. T., Smith, D. R., Cummings, B. J., Anderson, A. J., \& Shea, L. D. (2018). Reducing inflammation through delivery of lentivirus encoding for anti-inflammatory cytokines attenuates neuropathic pain after spinal cord injury. Journal of Controlled Release, 290 , 88-101. doi:10.1016/j.jconrel.2018.10.003

Pawar, K., Cummings, B. J., Thomas, A., Shea, L. D., Levine, A., Pfaff, S., \& Anderson, A. J. (2015). Biomaterial bridges enable regeneration and re-entry of corticospinal tract axons into the cau- 
dal spinal cord after SCI: Association with recovery of forelimb function.Biomaterials, 65 , 1-12. doi:10.1016/j.biomaterials.2015.05.032

Pereira, I. M., Marote, A., Salgado, A. J., \& Silva, N. A. (2019). Filling the Gap: Neural Stem Cells as A Promising Therapy for Spinal Cord Injury. Pharmaceuticals (Basel, Switzerland), 12 (2), 65. doi:10.3390/ph12020065

Sakuma, T., Barry, M. A., \& Ikeda, Y. (2012). Lentiviral vectors: basic to translational. Biochem J, 443 (3), 603-618. doi:10.1042/bj20120146

Shahriari, D., Koffler, J. Y., Tuszynski, M. H., Campana, W. M., \& Sakamoto, J. S. (2017). Hierarchically Ordered Porous and High-Volume Polycaprolactone Microchannel Scaffolds Enhanced Axon Growth in Transected Spinal Cords. Tissue Eng Part A, 23 (9-10), 415-425. doi:10.1089/ten.TEA.2016.0378

Shamash, S., Reichert, F., \& Rotshenker, S. (2002). The cytokine network of Wallerian degeneration: tumor necrosis factor-alpha, interleukin-1alpha, and interleukin-1beta. The Journal of neuroscience : the official journal of the Society for Neuroscience, 22 (8), 3052-3060. doi:10.1523/JNEUROSCI.22-08-03052.2002

Shikanov, A., Smith, R. M., Xu, M., Woodruff, T. K., \& Shea, L. D. (2011). Hydrogel network design using multifunctional macromers to coordinate tissue maturation in ovarian follicle culture.Biomaterials, 32 (10), 2524-2531. doi:10.1016/j.biomaterials.2010.12.027

Shin, S., Salvay, D. M., \& Shea, L. D. (2010). Lentivirus delivery by adsorption to tissue engineering scaffolds. Journal of biomedical materials research. Part A, 93 (4), 1252-1259. doi:10.1002/jbm.a.32619

Shrestha, B., Coykendall, K., Li, Y., Moon, A., Priyadarshani, P., \& Yao, L. (2014). Repair of injured spinal cord using biomaterial scaffolds and stem cells. Stem Cell Research 83 Therapy, 5 (4), 91. doi:10.1186/scrt480

Skoumal, M., Seidlits, S., Shin, S., \& Shea, L. (2016). Localized lentivirus delivery via peptide interactions. Biotechnology and Bioengineering, 113 (9), 2033-2040. doi:https://doi.org/10.1002/bit.25961

Smith, D. R., Dumont, C. M., Park, J., Ciciriello, A. J., Guo, A., Tatineni, R., . . Shea, L. D. (2020). Polycistronic Delivery of IL-10 and NT-3 Promotes Oligodendrocyte Myelination and Functional Recovery in a Mouse Spinal Cord Injury Model. Tissue Engineering Part A . doi:10.1089/ten.tea.2019.0321

Smith, D. R., Margul, D. J., Dumont, C. M., Carlson, M. A., Munsell, M. K., Johnson, M., . . Shea, L. D. (2019). Combinatorial lentiviral gene delivery of pro-oligodendrogenic factors for improving myelination of regenerating axons after spinal cord injury. Biotechnol Bioeng, 116 (1), 155-167. doi:10.1002/bit.26838

Soderblom, C., Luo, X., Blumenthal, E., Bray, E., Lyapichev, K., Ramos, J., . . Lee, J. K. (2013). Perivascular Fibroblasts Form the Fibrotic Scar after Contusive Spinal Cord Injury. The Journal of Neuroscience, 33 (34), 13882. doi:10.1523/JNEUROSCI.2524-13.2013

Straley, K. S., Foo, C. W. P., \& Heilshorn, S. C. (2010). Biomaterial design strategies for the treatment of spinal cord injuries. Journal of neurotrauma, 27 (1), 1-19. doi:10.1089/neu.2009.0948

Tejeda, G., Ciciriello, A. J., \& Dumont, C. M. (2021). Biomaterial Strategies to Bolster Neural Stem CellMediated Repair of the Central Nervous System. Cells Tissues Organs .

Temple, S., \& Studer, L. (2017). Lessons Learned from Pioneering Neural Stem Cell Studies. Stem Cell Reports, 8 (2), 191-193. doi:10.1016/j.stemcr.2017.01.024

Tetzlaff, W., Okon, E. B., Karimi-Abdolrezaee, S., Hill, C. E., Sparling, J. S., Plemel, J. R., . . . Kwon, B. K. (2011). A systematic review of cellular transplantation therapies for spinal cord injury. Journal of neurotrauma, 28 (8), 1611-1682. doi:10.1089/neu.2009.1177

Thomas, A. M., Kubilius, M. B., Holland, S. J., Seidlits, S. K., Boehler, R. M., Anderson, A. J., . . Shea, L. D. (2013). Channel density and porosity of degradable bridging scaffolds on axon growth after spinal injury. Biomaterials, 34 (9), 2213-2220. doi:10.1016/j.biomaterials.2012.12.002 
Thomas, A. M., Seidlits, S. K., Goodman, A. G., Kukushliev, T. V., Hassani, D. M., Cummings, B. J., . . Shea, L. D. (2014). Sonic hedgehog and neurotrophin-3 increase oligodendrocyte numbers and myelination after spinal cord injury. Integr Biol (Camb), 6 (7), 694-705. doi:10.1039/c4ib00009a

Tsintou, M., Dalamagkas, K., \& Seifalian, A. M. (2015). Advances in regenerative therapies for spinal cord injury: a biomaterials approach. Neural regeneration research, 10 (5), 726-742. doi:10.4103/1673-5374.156966

Tuinstra, H. M., Aviles, M. O., Shin, S., Holland, S. J., Zelivyanskaya, M. L., Fast, A. G., . . Shea, L. D. (2012). Multifunctional, multichannel bridges that deliver neurotrophin encoding lentivirus for regeneration following spinal cord injury. Biomaterials, 33 (5), 1618-1626. doi:10.1016/j.biomaterials.2011.11.002

Tuinstra, H. M., Margul, D. J., Goodman, A. G., Boehler, R. M., Holland, S. J., Zelivyanskaya, M. L., ... Shea, L. D. (2013). Long-Term Characterization of Axon Regeneration and Matrix Changes Using Multiple Channel Bridges for Spinal Cord Regeneration. Tissue Engineering Part A, 20 (5-6), 127-1037. doi:10.1089/ten.tea.2013.0111

Yang, Y., Laporte, L. D., Zelivyanskaya, M. L., Whittlesey, K. J., Anderson, A. J., Cummings, B. J., \& Shea, L. D. (2009). Multiple Channel Bridges for Spinal Cord Injury: Cellular Characterization of Host Response. Tissue Engineering Part A, 15 (11), 3283-3295. doi:10.1089/ten.tea.2009.0081

Yang, Z., Zhang, A., Duan, H., Zhang, S., Hao, P., Ye, K., . . L Li, X. (2015). NT3-chitosan elicits robust endogenous neurogenesis to enable functional recovery after spinal cord injury. Proc Natl Acad Sci U S A, 112 (43), 13354-13359. doi:10.1073/pnas.1510194112

Zhao, J., Pettigrew, G. J., Thomas, J., Vandenberg, J. I., Delriviere, L., Bolton, E. M., . . Lever, A. M. (2002). Lentiviral vectors for delivery of genes into neonatal and adult ventricular cardiac myocytes in vitro and in vivo. Basic Res Cardiol, 97 (5), 348-358. doi:10.1007/s00395-002-0360-0

Zhu, Y., Soderblom, C., Trojanowsky, M., Lee, D.-H., \& Lee, J. K. (2014). Fibronectin Matrix Assembly after Spinal Cord Injury.Journal of neurotrauma, 32 (15), 1158-1167. doi:10.1089/neu.2014.3703

Figure 1: FLuc loaded PEG tubes sustained expression over a course of 12 weeks. Qualitatively, (A) bioluminescence was detected in highest concentrations at the injured spinal cord. (B) Bioluminescent signal of lentivirus-laden hydrogel tubes was assessed over a course of 12 weeks with higher expression compared to background across all times evaluated. $\mathrm{n}=6$ per condition, ${ }^{*} \mathrm{p}<0.05,{ }^{* *} \mathrm{p}<0.01,{ }^{* * * *} \mathrm{p}<0.001$.

Figure 2: Macrophage infiltration is not exacerbated by tube implantation or E14 spinal progenitor transplantation. Macrophage densities in (A) SCI only, (B) Tubes only, (C)Tubes+IL-10, (D) E14 spinal progenitors only, (E) Tubes+E14, and (F) Tubes+E14+IL-10 in transverse tissue cross sections exhibit both M1 macrophages $\left(\mathrm{F} 4 / 80^{+}\right.$, red) denoted by ${ }^{\wedge}$ and $\mathrm{M} 2$ macrophages $\left(\mathrm{F} 4 / 80^{+} \operatorname{arginase}^{+}\right.$, red and green) denoted by *. At 4 weeks after implantation, there were no differences in $(\mathrm{G})$ total macrophage density, $(\mathrm{H})$ M2 macrophage density, and (I) M2 percent across all conditions. Data are presented as mean \pm SEM. $n=4$ per condition, $50 \mu \mathrm{m}$ scale bars.

Figure 3: (A) Experimental timeline detailed with major interventions. Delayed $\mathrm{EGFP}^{+}$spinal progenitor transplantation into IL-10 encoding lentivirus loaded tubes 2 weeks post-injury improves survival. Five hydrogel tubes, either blank or IL-10 lentivirus loaded, were implanted directly after lateral C5 hemisection injury, and $\mathrm{EGFP}^{+}$spinal progenitors were transplanted 2 weeks post-injury into (B) SCI only, (C) blank tubes, or (D) IL-10 lentivirus loaded tubes. Quantitatively, survival was assessed 4 weeks post-injury (2 weeks post-transplantation), and IL-10 lentivirus loaded tubes exhibited an increase in (E) cell density and (F) percent survival over the other two conditions. Data are presented as mean \pm SEM. $\mathrm{n}=4$ per condition, ${ }^{*} \mathrm{p}<0.05,{ }^{* *} \mathrm{p}<0.01,50 \mu \mathrm{m}$ scale bars.

Figure 4: Neuron formation at 12 weeks post-injury is increased when hydrogel tubes are implanted. (A) Formed neurons were observed at 12 weeks post-injury arising from both exogenous $\left(\mathrm{EGFP}^{+} \mathrm{NeuN}^{+} \mid\right.$green $^{+}$gray $^{+}$, green arrow $)$and endogenous $\left(\mathrm{BrdU}^{+} \mathrm{NeuN}^{+} \mid \mathrm{red}^{+}\right.$gray $^{+}$, pink arrow $)$sources 
(B) No statistically significant differences was observed in exogenous-sourced neuron density. (C) A significant increase in $\mathrm{NeuN}^{+}$cells as a percent of total $\mathrm{EGFP}^{+}$cells was observed when E14 spinal progenitors were transplanted into either blank tubes or IL-10 lentivirus-loaded tubes. (D) There were no statistically significant differences observed in endogenous-sourced neuron formation. Data are represented as mean \pm SEM, $\mathrm{n}=4-7$ animals per conditions, ${ }^{*} \mathrm{p}<0.05,{ }^{* *} \mathrm{p}<0.01,50 \mu \mathrm{m}$ scale bars.

Figure 5: E14 spinal progenitor transplants into IL-10 lentivirus-laden tubes improve new axon formation at 12 weeks post-injury. Axon expression $\left(\mathrm{NF}-200^{+}\right)$in (A) SCI only, (B) Tubes only, (C) Tubes+IL-10, (D) E14 spinal progenitors only, (E) Tubes+E14, and (F) Tubes+E14+IL-10. Examples of (G) bundles and $(\mathrm{H})$ elongated axons observed in the ipsilateral tissue. Quantitatively, animals receiving Tubes+E14+IL-10 exhibited a higher elongated axon density (I) in the ipsilateral tissue. Data are presented as mean \pm SEM. $\mathrm{n}=6$ animals per condition, ${ }^{*} \mathrm{p}<0.05,{ }^{* *} \mathrm{p}<0.01,{ }^{* * *} \mathrm{p}<0.005,200 \mu \mathrm{m}$ scale bars (A-F), $50 \mu \mathrm{m}$ scale bars (G-H).

Figure 6: E14 spinal progenitor delivery increases axon remyelination 12 weeks post-injury. Axon (NF$200^{+}$, red) co-localization with myelin $\left(\mathrm{MBP}^{+}\right.$, green) was assessed in (A) SCI only, (B) Tubes only, (C) Tubes+IL-10, (D) E14 spinal progenitors only, (E) Tubes+E14, and (F) Tubes+E14+IL-10. (G) E14 only transplants and Tubes+E14+IL-10 exhibited an increase in overall myelinated axon density compared to the SCI only condition. (H) As a percent, myelination was significantly increased in the E14 only condition compared to all other conditions. Data are represented as mean \pm SEM, $n=4-7$ animals per condition, ${ }^{*}$ $\mathrm{p}<0.05,{ }^{* *} \mathrm{p}<0.01,{ }^{* * *} \mathrm{p}<0.005,{ }^{* * * *} \mathrm{p}<0.001,20 \mu \mathrm{m}$ scale bars.

Figure 7: Animals receiving E14 spinal progenitors transplanted into IL-10 lentivirus-laden tubes exhibited a quicker return of forelimb motor function. To assess mobility, a horizontal ladder beam test was used. Mice were trained on walking across the ladder prior to injury. Mobility was assessed through successful placements as a score out of 50 possible rungs. By 4 weeks post-injury Tubes+E14+IL-10 (a, p $<0.005)$ had improved stepping compared to SCI only. At 8 weeks all conditions with tubes had improved stepping compared to (Tubes+E14, b, p <0.005; Tubes+IL-10, c, p $<0.05$; Tubes, d, p $<0.05$ ). At 12 weeks all conditions exhibited improved stepping (E14 only, e, $\mathrm{p}<0.01)$.
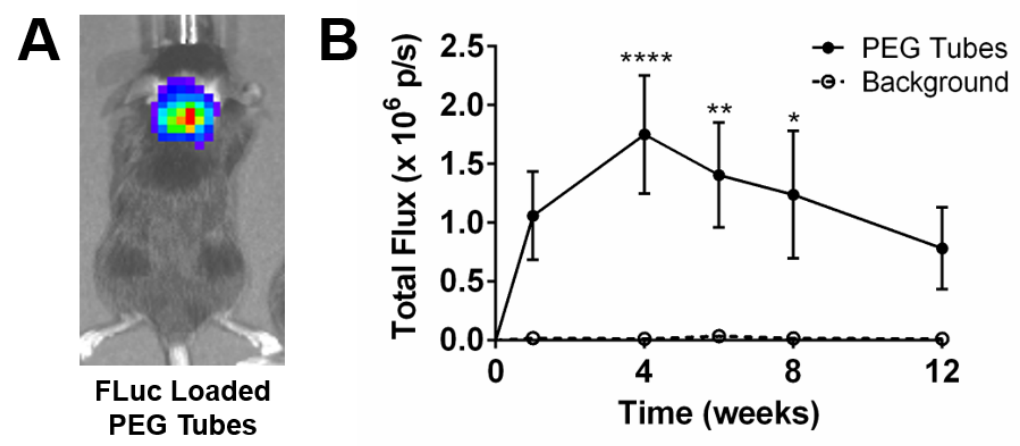

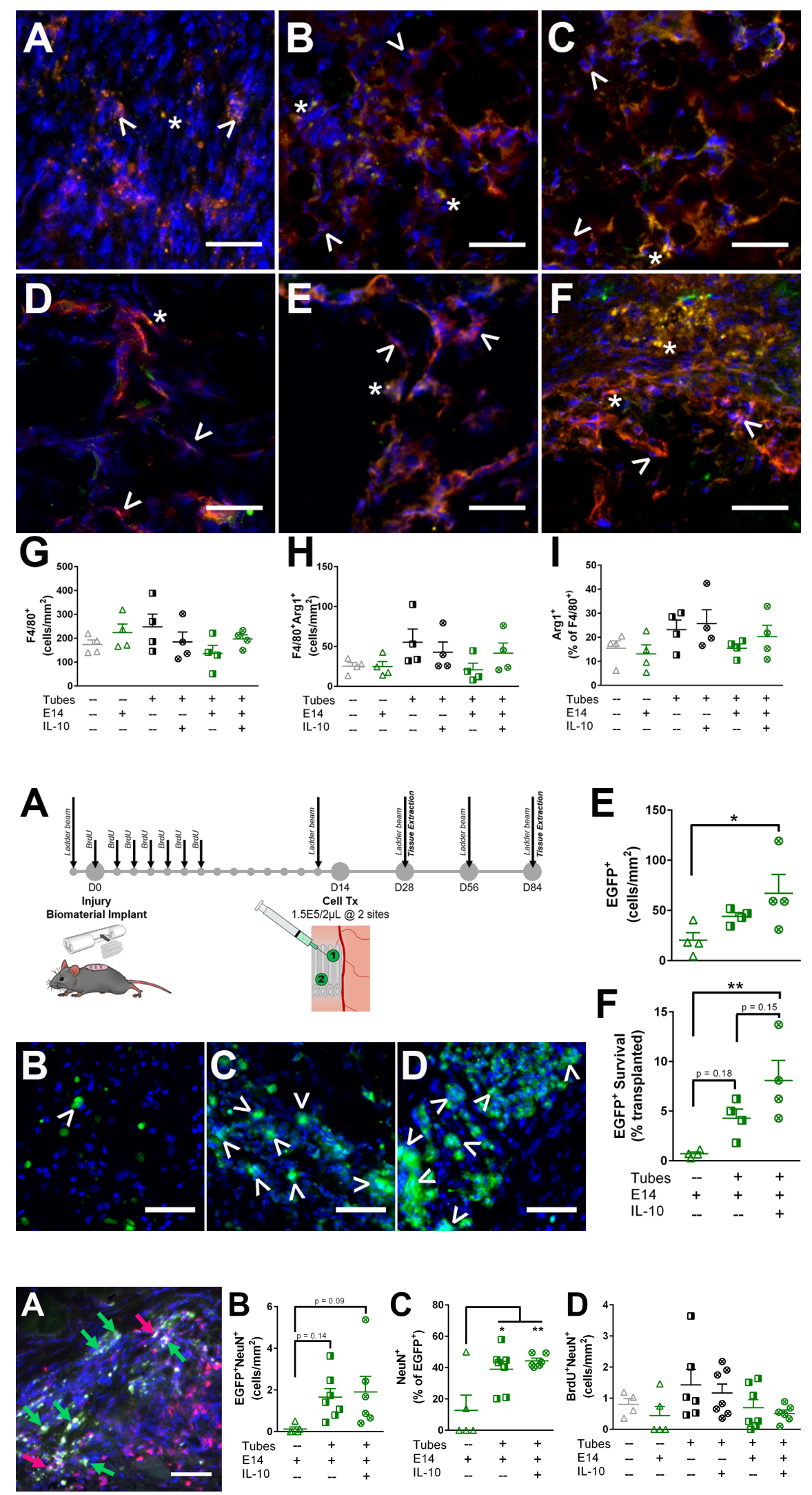


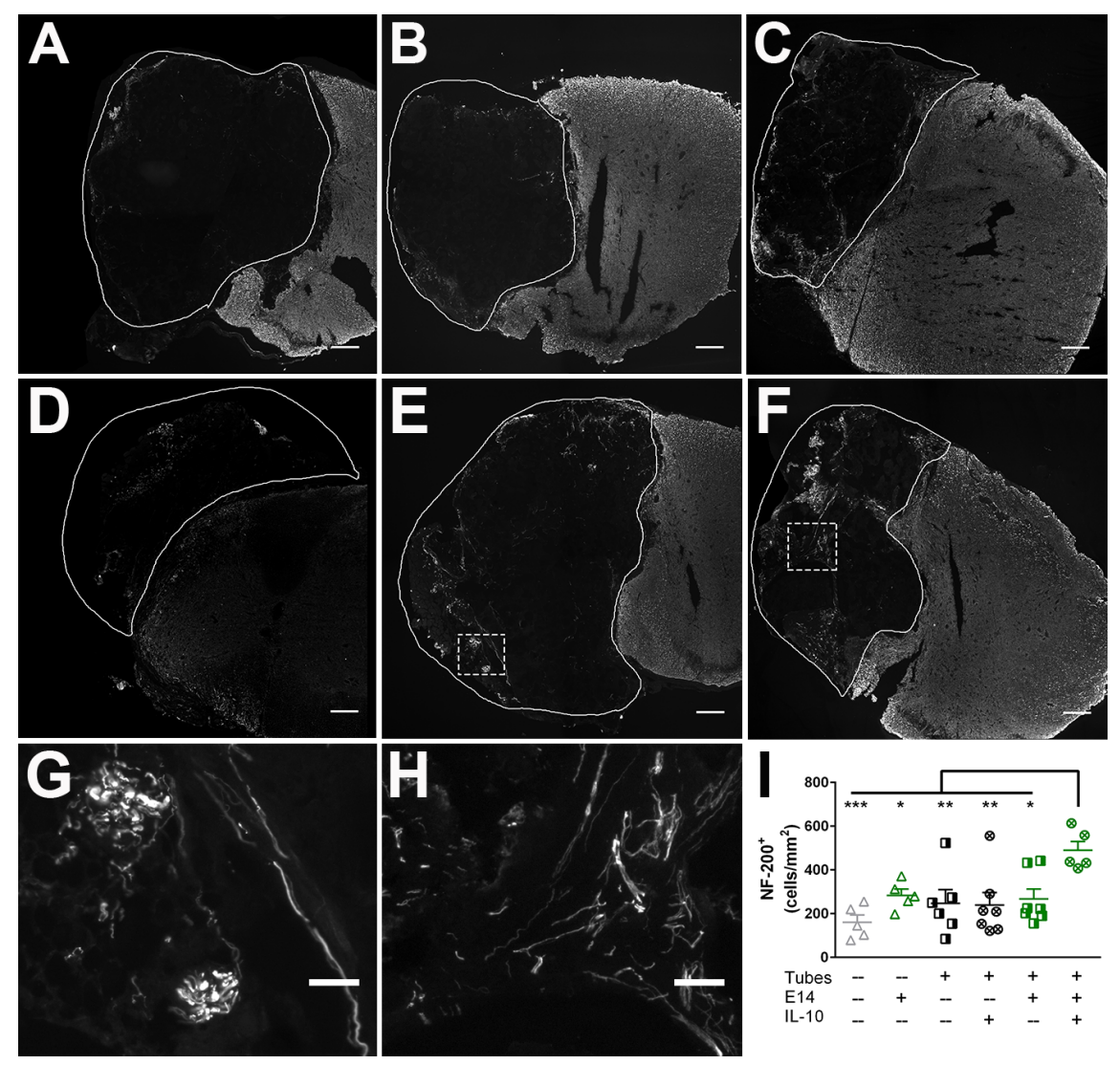



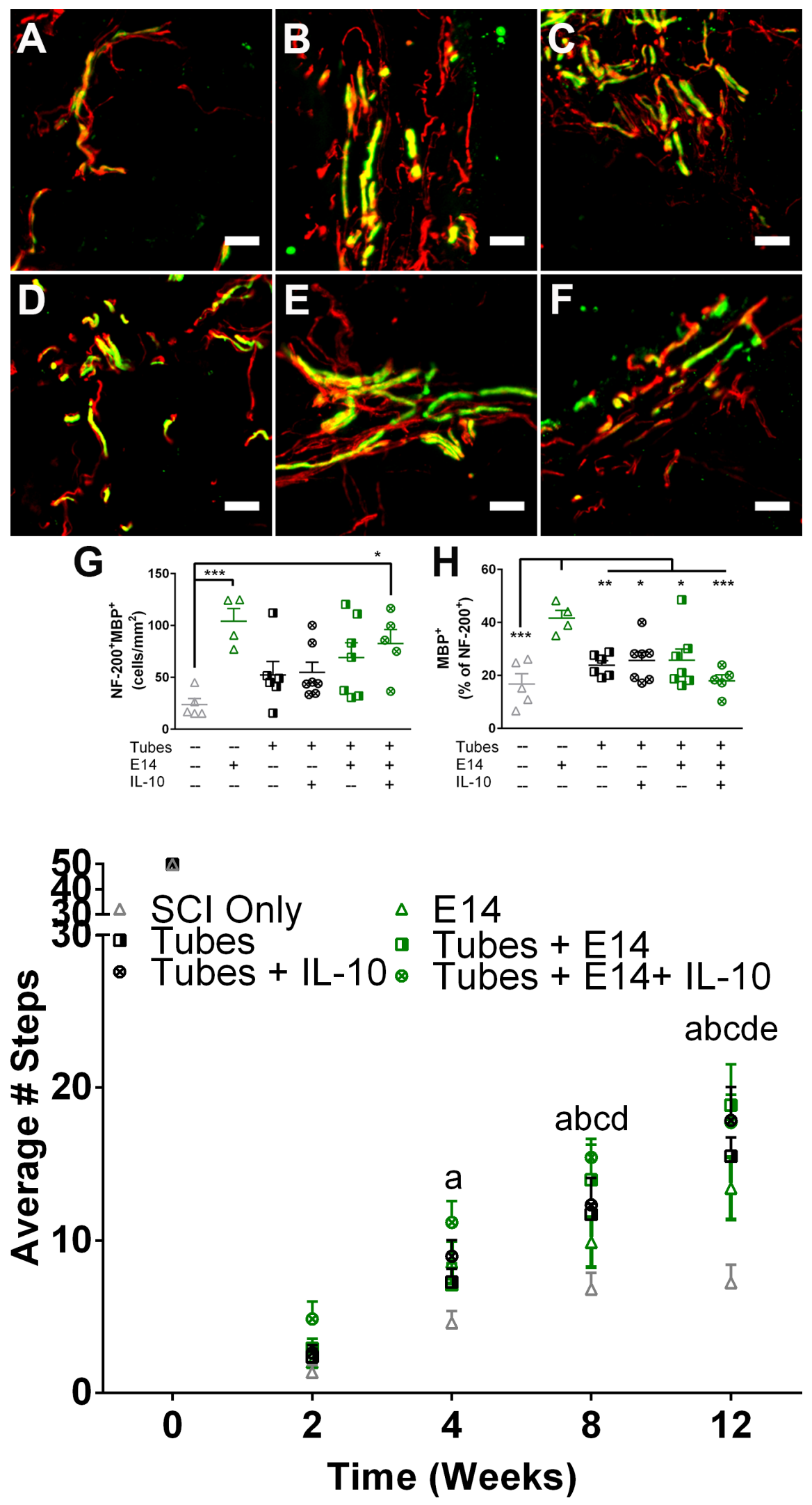